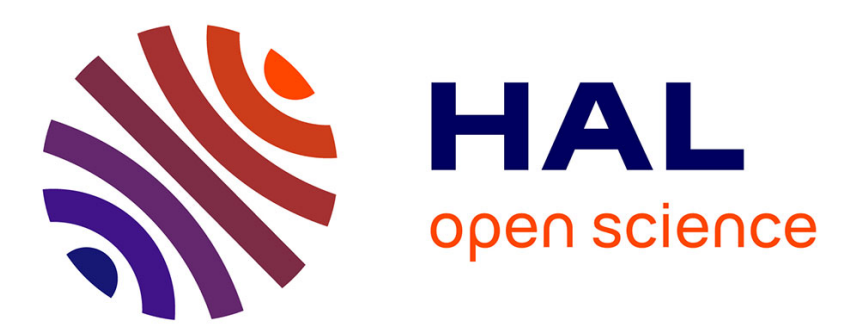

\title{
Multi-instrumentation monitoring for the curing process of a composite structure
}

\author{
Francis Collombet, Mauricio Torres, Bernard Douchin, Laurent Crouzeix, \\ Yves-Henri Grunevald, Jérôme Lubin, Thierry Camps, Xavier Jacob, Geert \\ Luyckx, K.-T Wu
}

\section{To cite this version:}

Francis Collombet, Mauricio Torres, Bernard Douchin, Laurent Crouzeix, Yves-Henri Grunevald, et al.. Multi-instrumentation monitoring for the curing process of a composite structure. Measurement - Journal of the International Measurement Confederation (IMEKO), 2020, 157, pp.107635. 10.1016/j.measurement.2020.107635 . hal-02501595

\section{HAL Id: hal-02501595 \\ https://hal.science/hal-02501595}

Submitted on 13 Mar 2020

HAL is a multi-disciplinary open access archive for the deposit and dissemination of scientific research documents, whether they are published or not. The documents may come from teaching and research institutions in France or abroad, or from public or private research centers.
L'archive ouverte pluridisciplinaire HAL, est destinée au dépôt et à la diffusion de documents scientifiques de niveau recherche, publiés ou non, émanant des établissements d'enseignement et de recherche français ou étrangers, des laboratoires publics ou privés. 


\section{Journal Pre-proofs}

Multi-instrumentation monitoring for the curing process of a composite structure

F. Collombet, M. Torres, B. Douchin, L. Crouzeix, Y-H. Grunevald, J. Lubin, T. Camps, X. Jacob, G. Luyckx, K-T. Wu

PII: S0263-2241(20)30172-X

DOI: https://doi.org/10.1016/j.measurement.2020.107635

Reference: MEASUR 107635

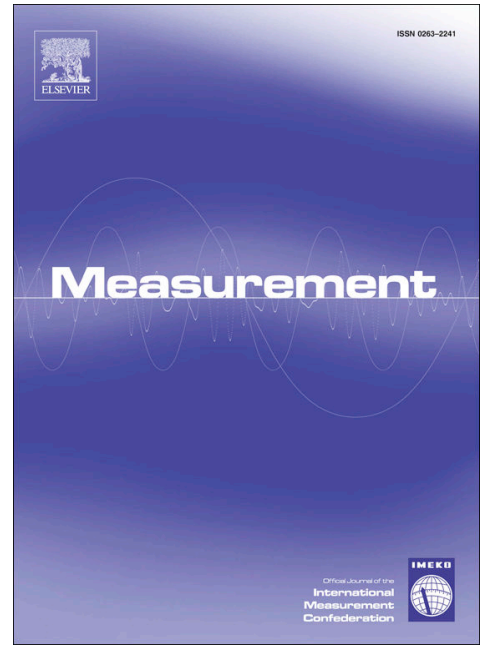

To appear in:

Measurement

Received Date: 25 September 2019

Revised Date: 16 January 2020

Accepted Date:

18 February 2020

Please cite this article as: F. Collombet, M. Torres, B. Douchin, L. Crouzeix, Y-H. Grunevald, J. Lubin, T. Camps, X. Jacob, G. Luyckx, K-T. Wu, Multi-instrumentation monitoring for the curing process of a composite structure, Measurement (2020), doi: https://doi.org/10.1016/j.measurement.2020.107635

This is a PDF file of an article that has undergone enhancements after acceptance, such as the addition of a cover page and metadata, and formatting for readability, but it is not yet the definitive version of record. This version will undergo additional copyediting, typesetting and review before it is published in its final form, but we are providing this version to give early visibility of the article. Please note that, during the production process, errors may be discovered which could affect the content, and all legal disclaimers that apply to the journal pertain.

(C) 2020 Published by Elsevier Ltd. 


\title{
MULTI-INSTRUMENTATION MONITORING FOR THE CURING PROCESS OF A COMPOSITE STRUCTURE.
}

\author{
F. Collombet ${ }^{1}$, M. Torres ${ }^{* 1,7}$, B. Douchin ${ }^{1}$, L. Crouzeix ${ }^{1}$, Y-H. Grunevald ${ }^{2}$, J. Lubin ${ }^{3}$, \\ T. Camps ${ }^{3}$, X. Jacob ${ }^{4}$, G. Luyckx ${ }^{5}$, K-T. Wu 6 . \\ 1 Université Fédérale Toulouse Midi-Pyrénées / UMR CNRS 5312 - Institut Clément Ader, \\ 3 Rue Caroline Aigle, 31400 Toulouse, Francia. \\ 2 Composites, Expertise \& Solutions, 4 Rue Georges Vallerey, F-31320 Castanet Tolosan, France. \\ 3 Université de Toulouse, Laboratory for Analysis and Architecture of Systems (LAAS), Toulouse, France. \\ 4 Université Fédérale Toulouse Midi-Pyrénées, Laboratory of Human Being Physics Applied to the Environment
}

(PHASE),

118 Route de Narbonne, 31062, Toulouse, France.

5 Department of Materials Science and Engineering, Ghent University,

41 Sint-Pietersnieuwstraat, 9000 Ghent, Belgium.

6 Industrial Materials Institute, National Research Council of Canada,

75 Boulevard de Mortagne, Boucherville, Quebec J4B6Y4, Canada.

7 CONACYT - CIDESI, National Center for Aeronautics Technologies, Carretera Estatal 200, 76259,

Querétaro, México

\begin{abstract}
The phenomena occurring during curing process is one of the major issues to deal in order to improve the physical properties of a composite structure. In this work, a multi-instrumentation setup is conceived in order to have a better understanding of composites curing using different devices (tunnelling junction sensors, optical fibres and flexible ultrasonic transducers). The sensors are simultaneously embedded or placed on the surface of a thick carbon-epoxy plate for monitoring its autoclave cycle. By means of all signals, an evolution of temperature, internal strains and physical state changes is described. A qualitative statement from all measurements is provided to have a first approach of the initial state of the composite plate. With this methodology, the initial state after composite manufacturing can be considered in the structure design procedure to improve its mechanical performance.
\end{abstract}

Keywords: curing process, carbon-epoxy plate, tunnelling junction sensor, optical fibres, flexible ultrasonic transducers.

*Corresponding Author, E-mail: maothor@gmail.com, mtorresar@conacyt.mx (M. Torres) 


\section{Introduction}

The quality control of long-fibre composite structures represents a technical and economical challenge for many industries such as aeronautics, aerospace and fluids transport. The nature of their constitutive layers allows the possibility to implement in-core instrumentation for monitoring since the manufacturing process until their final application. Numerous studies have proven the value added of composites in-core instrumentation to follow through-the-thickness properties [1-3]. However, composites in-core instrumentation still reveals worries which retard its plenty application. Sensor's size, autonomy and wire connexions are the major issues to deal with in order to fulfil this approach in the industry.

The use of bulk sensors on composites from different technologies and principles have been widely study [4-11]. A rough classification could gather them in two main categories: 1) electrical devices and 2) optical devices. On one hand, electrical devices take advantage of the conversion of external stimuli into an electric change, in terms of resistance, current or potential. On this classification we can find thermocouples [8, 9], pressure transducers [10], piezoelectric sensors $[11,19]$ and dielectric analysis devices (DEA) [12, 13]. On the other hand, optical devices take advantage of the perturbation of a light beam, in terms of wavelength or period, to quantify an external phenomenon. Optical fibre devices can be distinguished on those working based on Snell's law [5-7] and those based on Bragg's refraction index [2-4, 14, 15].

Based on the state-of-the-art knowledge, new sensors based on improved materials' science features have been promoted. On the electric devices side, tunnelling junction sensors (TJS) $[16,17]$ and flexible ultrasonic transducers (FUT) [18-20] are attracting researchers' attention. On the optical devices side, micro-structured optical fibres (MOF) [21-25] have been developed in order to maximize the quantification of the light beam perturbation. These recent technologies have been showed efficient diagnosis on the thermal phenomena which occur during composites curing. A deeper knowledge of the curing reaction will aid to reply on many snags that appear in the fabrication stage and, in consequence, will improve the mechanical properties of the composite structure [26-30].

Other approaches for composites in-situ monitoring involves new technologies for self-sensing components. Smart modified fabrics [31-34] and smart modified resins [35, 36], mostly by adding carbon nanotubes (CNT), are taking advantage of key processing approaches for 
nanotube/fiber hybridization and its application as sensors. On one side, coated fabrics with carbon nanomaterials, have been subjected to compaction and flow monitoring tests, showing promising results. On the other side, the addition of nanoparticles on thermoset resins, at relatively low volume fractions, form electrically conductive networks. The electrical conductivity of the network is sensitive to deformation, temperature, and other external stimuli [32, 33, 37]. CNT, graphene coated, and carbon fibre sensors have been developed for monitoring complete moulding process through the real-time resistance change [38]. The nanoreinforcement sensor approach can be extended, not only for manufacturing track, but also for diagnosing and evaluating the health stages of polymeric composites on in-service conditions and failure. Despite all these current features, industrialization and cost-benefit issues, regarding large "smart composites" production, limit the application of these approaches. It is true that a single system could not afford the life-span of the composite component. At the end, sensing methods, which modify the less the industrial lines, are the ones that are most attractive to industry partners [39].

The project called "Multi-sensor Instrumentation for the Composite Materials and Structures (I2MC)" puts together the expertise of seven research teams with the goal to study the in-core instrumentation of composites structures by applying the Multi-Instrumented Technological Evaluator toolbox (MITE toolbox) [40-42].

In this collaboration, the members of the project propose a multi-instrumentation set up for monitoring a composite structure during its curing process. The main goal is to compare the signals from different embedded devices such as tunnelling junction sensors (TJS), flexible ultrasonic transducers (FUT) and micro-structured optical fibres (MOF). Sensors sensitivity for detecting temperature changes as well as residual stresses and strains are evaluated in order to confirm its performance for curing's monitoring.

In this paper, the capability of the different sensors to acquire complementary information from the polymerization process is labelled. The goal is to have a general overview of the devices used, experimental setup as well as the first results. First, a global explanation of the experimental set up is provided. Then, a comparison between each embedded sensors signal (TJS, FUT and MOF) with the reference thermocouples measurements is discussed. Finally, the concluding remarks and further work are addressed. 


\section{Sensing devices and subject of testing}

\subsection{Tunnelling junction sensors (TJS)}

Tunnelling junction sensors (TJS) are electronic devices which take advantage of inverse polarization of $\mathrm{P}-\mathrm{N}$ junctions. During the last decade, the LAAS has tested the TJS on microfluids applications and as thermal micro-actuators [16, 17]. The TJS consist in a silicon polycrystalline prism doped with Phosphorus and Bore by low-pressure chemical vapour deposition (LPCVD) to form $\mathrm{P}-\mathrm{N}$ junctions. The $\mathrm{P}-\mathrm{N}$ junction, known as Symmetric Thresholds Element (STE), can be considered electrically as two Zener diodes connected by the cathode. A schematic of the TJS configuration is shown in figure 1-a.

To stimulate the $\mathrm{P}-\mathrm{N}$ junctions, the TJS is polarized continuously. In other words, the TJS receive a range of electrical current and returns a range of electrical voltage. For a current polarization value below $100 \mathrm{nA}$, the voltage is zero because the electrons of the $\mathrm{P}-\mathrm{N}$ junctions do not have enough energy to cross the potential barrier. Between $100 \mathrm{nA}$ and $10 \mathrm{~mA}$, the increment of energy produces the shrinkage of the potential barrier, allowing the electrons to pass through it and the voltage increases gradually. This fact is a pure quantum physics phenomenon, known as "tunnelling effect" or "tunnelling effect conduction". After $10 \mathrm{~mA}$, the energy increases exponentially giving to the electron flux a free way through the $\mathrm{P}-\mathrm{N}$ junctions. The equivalent circuit of the TJS is illustrated in the figure 1-b.

The interest on the tunnelling effect conduction lays onto its dependence to temperature changes [16]. The sensibility to temperature changes becomes evident when the polarization current gets a value within the tunnel effect interval. For a fixed polarization current, the voltage will fluctuate as regards on the increment or decrease of temperature. This condition makes the TJS affordable for monitoring temperature changes.

TJS employed in this study case have $2 \times 2 \times 0.3 \mathrm{~mm}$ as nominal dimensions and they are glued onto a flex Kapton ${ }^{\circledR}$ wire, as depicted in figure 1-c. For TJS polarization, a SMU 2612 Keithley ${ }^{\circledR}$ power source controlled by Labtracer software is used. Efficient study cases of TJS manufacturing and electrical-thermal response are fully described in $[16,17]$.

\subsection{Flexible Ultrasonic Transducers (FUT)}

Flexible ultrasonic transducers (FUT) are one of the non-destructive techniques (NDT) which can be used to reveal the presence of internal defects in a structure. Nowadays, several 
researches are interested in the ultrasonic transducer to infer some phenomena during composites fabrication or mechanical loading.

FUT works thanks to the piezoelectric effect of their constitutive micro-layers. By receiving an electrical stimulation, the FUT produce a high-frequency wave that can travel through any material which the FUT is in contact to. The parameters of the ultrasonic wave after travelling are unique and it depends only on the atomic composition and the physical state of each material. Therefore, if a defect exists inside the monitored material, the wave parameters such as the amplitude or the delay time will change.

The FUT employed on this work are composed by bismuth titanate (BIT) powders dispersed by sol-gel spray onto a lead-zirconate-titanate (PZT) substrate of $4 \mathrm{~mm}$ diameter. Then, this compound is placed onto a stainless-steel foil of $12.7 \mathrm{~mm}$ length. This disposition gives the FUT their main characteristics: flexibility, good ultrasonic coupling with the sample to measure and functioning at relatively high temperature $\left(<500^{\circ} \mathrm{C}\right)[18,19]$. This last characteristic makes the FUT very promising for monitoring composites during their curing process.

During all polymerization cycle, FUT are stimulated producing different echoes which travel through-the-thickness of the composite plate. On this work, only the echoes generated by the FUT at the mould's side are treated. These echoes are illustrated in figure 2 and described as follows:

- $\quad \mathrm{L}_{\mathrm{m}+\mathrm{c}}$ : echo generated by the FUT at the mould's side which travels through the rod and it is received by the FUT at the composite's side.

- $\quad \mathrm{L}_{\mathrm{m}+3 \mathrm{c}}$ : echo generated by the FUT at the mould's side which travels through the rod and the composite, it rebounds inside the composite and it is received by the FUT at the composite's side.

- $\quad \mathrm{L}_{2 \mathrm{~m}}$ : echo generated by the FUT at the mould's side which travels through the rod, it rebounds at the mould - composite interface and it returns to the FUT at mould's side.

- $\quad \mathrm{L}_{2 \mathrm{~m}+2 \mathrm{c}}$ : echo generated by the FUT at the mould's side which travels through the rod and the composite, it rebounds at the FUT - composite interface and it returns to the FUT at mould's side. 
As the thickness of the composite plate is being modified during the curing cycle, the parameters of the echoes recorded (amplitude and the delay of time) can give indications of the different polymerization stages.

\subsection{Microstructured Optical Fibres (MOF)}

Fibre Bragg Gratings (FBG) are currently employed in composite structures to follow physical phenomena inside their plies [21-26]. Nowadays FGB's implementation needs to be involved from the composite manufacturing process until the composite's failure. However, due to the thermo-mechanical coupling of the in-situ spectra, additional signal treatments must be done in order to have reliable information. Furthermore, the discrimination of thermal data (temperature) from the mechanical data (axial strains) stays laborious and sensible to the type of optical fibre [22]. Moreover, the transverse strains resulting from the curing reaction, are often not detected or denied from the FBG's response. These transverse perturbations must be considered with the purpose of having a proper interpretation of the FBG's recovered signals $[21,23,24]$.

Most of the FBG instrumentation only detects the temperature variations and strains fluctuations in the axial direction of the optical fibre. Nonetheless, transverse strains are also interesting to analyse because their link with residual stresses that often appear in the course of composites curing $[24,26]$. Measurement of transverse strains inside composites has been proposed with Microstructured Optical Fibres (MOF) [25]. These innovating sensors have an array of air-holes inside their doped core. This microstructural characteristic makes them very sensible to transverse strains $[27,28]$.

MOF used in this study have a $125 \mu \mathrm{m}$ diameter Germanium doped core with three air-holes. Thanks to their birefringence nature, non-polarized light is used to produce two Bragg peaks $\left(\lambda_{B 1}\right.$ and $\lambda_{B 2}$ ) corresponding to each orthogonally polarized mode propagating inside the optical fibre. The peaks' separation $(\Delta \lambda)$ is related to the phase modal birefringence $(B)$ and the grating period in the fibre core $(\Lambda)$. The relation between all these parameters can be written in the following expression:

$$
\Delta \lambda=\lambda_{B 2}-\lambda_{B 1}=2 \times B \times \Lambda
$$

The peaks' separation is considered the MOF main parameter, instead of the individual wavelengths. This approach simplifies signal detection because no reference wavelength is 
needed. The sensitivity to transverse strains can be derived with the value of the modal phase birefringence $(B)$ if the grating period $(\Lambda)$ is constant. Additionally, one of the major advantages of MOF is their low sensitivity of peaks' separation to temperature changes; therefore, no thermo-mechanical coupling in the signal will appear $[25,27]$.

During curing cycle, the seven embedded MOF are actives and their optical signals are analysed by a si425 Micron Optics spectra analyser. An illustration of the cross-section of the MOF employed in this work and its initial spectrum are depicted in figure 3.

\subsection{Subject of testing, composite structure}

The composite structure studied here is a M10 HS300 carbon-epoxy plate of $230 \times 640 \mathrm{~mm}$ with two drop-offs as shown in figure 4. The composite plate has three zones with different thickness. In first place, the "current zone" has 20 plies with a quasi-isotropic lay-up: [0/45/0/45/0/45/0/-45/0/90]s. Then, the "thick zones" have 36 plies with the following lay-up: [0/45/0/45/0/45/0/-45/0/90/0/45/0/-45/0/45/0/-45] s. Finally the "over-thick zone" has 52 plies with the next lay-up: [90/0/0/90/0/45/0/-45/0/45/0/-45/0/90/0/45/0/-45/0/45/0/-45/0/90/90/0 $]_{\mathrm{s}}$. The drop-off zones are built with a $2.5 \mathrm{~mm}$ single latter step from the $11^{\text {th }}$ ply to the $26^{\text {th }}$ ply. This type of structure is representative of the design singularities currently found in aeronautics.

\section{Experimental set up}

The multi-instrumentation of the composite structure can be divided in two sets: the in-core instrumentation and the surface instrumentation.

The in-core instrumentation involves the following sensors, as shown in figure 5:

- a monitoring patch with a tunnelling junction sensor (TJS) on the $7^{\text {th }}$ ply at the centre of the current zone (patch 1);

- a monitoring patch with a tunnelling junction sensor (TJS) on the $18^{\text {th }} \mathrm{ply}, 50 \mathrm{~mm}$ after the end of the drop-off on the thick zone (patch 2);

- a micro-structured optical fibre on the $7^{\text {th }}$ ply, $50 \mathrm{~mm}$ above the central line of the plate (DTG ${ }^{\mathrm{TM}}$ CAP 1);

- a micro-structured optical fibre on the $7^{\text {th }}$ ply, $50 \mathrm{~mm}$ below the central line of the plate (DTG ${ }^{\text {TM }}$ Strip 1);

- a micro-structured optical fibre on the $7^{\text {th }}$ ply, $5 \mathrm{~mm}$ above the central line of the plate (DTG ${ }^{\mathrm{TM}}$ CAP 2); 
- a micro-structured optical fibre on the $7^{\text {th }}$ ply $5 \mathrm{~mm}$ below the central line of the plate (DTG ${ }^{\mathrm{TM}}$ Strip 3);

- two micro-structured optical fibres on the $26^{\text {th }}$ ply at the over-thick zone (DTG ${ }^{\mathrm{TM}}$ Strip 2 and PCF Strip 1);

- a micro-structured optical fibre on the $10^{\text {th }}$ ply at the middle of the current zone (PCF Strip 2).

The surface instrumentation involves the following sensors:

- a pair of flexible ultrasonic transducers (FUT) at the centre of the over-thick zone (FUT 1);

- a pair of flexible ultrasonic transducers (FUT) at the centre of the current zone (FUT 2);

- a pair of flexible ultrasonic transducers (FUT) at the current zone, $55 \mathrm{~mm}$ below the central line of the plate (FUT 3);

- a pair of flexible ultrasonic transducers (FUT) at the thick zone, $50 \mathrm{~mm}$ after the end of the drop-off (FUT 4);

- a pair of flexible ultrasonic transducers (FUT) at the thick zone, $50 \mathrm{~mm}$ before the end of the plate (FUT 5).

Then an assembly of thermocouples is installed in order to provide a reference for the temperature at the different zones of the plate:

- a thermocouple between the mould and the composite plate, $10 \mathrm{~mm}$ from the plate's lower side at the over-thick zone (TC1);

- a thermocouple on the $26^{\text {th }}$ ply at the centre of the over-thick zone (TC2);

- a thermocouple on the $50^{\text {th }}$ ply, $10 \mathrm{~mm}$ from the plate's upper side at the over-thick zone (TC3);

- a thermocouple between the mould and the composite plate, $10 \mathrm{~mm}$ from the plate's lower side at the current zone (TC4);

- a thermocouple on the $10^{\text {th }}$ ply, $10 \mathrm{~mm}$ from the plate's upper side at the current zone (TC5);

- a thermocouple on the $18^{\text {th }}$ ply, $10 \mathrm{~mm}$ from the plate's upper side at the current zone (TC6);

- a thermocouple between the mould and the composite plate, $10 \mathrm{~mm}$ from the plate's lower side and $10 \mathrm{~mm}$ from the end of the plate at the thick zone (TC7);

- a thermocouple on the $18^{\text {th }}$ ply, at the central line $10 \mathrm{~mm}$ from the end of the plate at the thick zone (TC8); 
- a thermocouple on the $34^{\text {th }}$ ply, $10 \mathrm{~mm}$ from the plate's upper side and $10 \mathrm{~mm}$ from the end of the plate at the thick zone (TC9).

Both, the surface instrumentation and reference thermocouples are shown in figure 6. All layup operations and embedding procedures are done manually with an appropriate environment in a grey room, in order to preserve the electronic and optical characteristics of all embedded devices. Illustrations of these procedures are shown in figure 7.

To have a better data acquisition during the curing process, adaptations to the mould and the wire connections are considered. In the case of the FUT, some adjustments are addressed on the metallic mould to acquire better measurements. With the aim to improve the parameters of the ultrasonic echoes, we increase the mould's thickness at the five FUT target points described before. The mould was drilled to obtain $30 \mathrm{~mm}$ diameter holes, then they are refilled with steel rods of $55 \mathrm{~mm}$ height, bonded with epoxy based glue. In this way, one device of each pair of FUT is placed below the rods. The other FUT device is placed face to the composite plate and surrounded by a silicone pyramid of $115 \times 55 \times 15 \mathrm{~mm}^{3}$. This adaptation is conceived to leave a softer print on the composite plate when the pressure rises inside the autoclave.

Other adaptations are provided to improve the passage of all wire connections outside the autoclave. For the MOF a pass-cable is used to exit the optical pig-tails. For the TJS and FUT, coaxial cables are connected to ceramic dominos which enable a correct exit for all cables. Illustrations of the general adaptations of the experimental set-up and the placement of the plate inside the autoclave are shown in figure 8.

The polymerization cycle begins at room temperature $\left(25^{\circ} \mathrm{C}\right)$. Then a $2^{\circ} \mathrm{C} / \mathrm{min}$ heating slope is provided to reach a $90^{\circ} \mathrm{C}$ plateau lasting $45 \mathrm{~min}$. After that, the temperature rises with the same $2^{\circ} \mathrm{C} / \mathrm{min}$ slope, to have a $120^{\circ} \mathrm{C}$ plateau lasting $2 \mathrm{hrs}$. When the second plateau ends, the cooling phase is fixed with a $-1^{\circ} \mathrm{C} / \mathrm{min}$ slope to get back at room temperature. For the pressure, we apply 2 bar from the beginning of the cycle until the end of the first temperature plateau. Then, the pressure is increased to 5 bar until the end of the polymerization cycle. During all the autoclave cycle, vacuum is fixed at 0.9 bar. The autoclave parameters are shown in figure 9 . Experimental setup was carried twice. As numerous sensors were employed, authors consider it enough due to the cost-benefit of the experimental campaign. 


\section{Results and discussion}

\subsection{Tunnelling junction sensors (TJS)}

A total of 45 TJS polarizations, from $1 \mathrm{nA}$ to $10 \mathrm{~mA}$, are induced during the curing cycle in order to follow the temperature changes inside the composite plate. The space of measurement of the TJS is detected between $2 \mathrm{~mA}$ and $5 \mathrm{~mA}$, where the sensitivity to temperature changes gets quantifiable. The voltage dependence to the temperature variation is illustrated in figure 10 .

In order to establish the link between the voltage variations of the TJS and the temperature changes of the composite plate, a temperature - voltage - time diagram is built. Figure 11 shows the TJS voltage variations for two current values, $2.75 \mathrm{~mA}$ and $3.8 \mathrm{~mA}$, and the temperature measurements of the thermocouple TC5 during the curing cycle. On this diagram, voltage decreases when the temperature rises and voltage increases when temperature diminishes. The TJS voltage has an inverse relation to the composite plate temperature. The TJS sensitivity at $2.75 \mathrm{~mA}$ is $-5.6 \pm 0.2 \mathrm{mV} /{ }^{\circ} \mathrm{C}$ and at $3.8 \mathrm{~mA}$ is $-5 \pm 0.2 \mathrm{mV} /{ }^{\circ} \mathrm{C}$. The TJS sensitivity has an average value of $-5 \pm 0.2 \mathrm{mV} /{ }^{\circ} \mathrm{C}$ for a current polarization between 2.5 and $4 \mathrm{~mA}[16]$.

With these results, the trustworthiness of using tunnelling junction sensors for composites curing monitoring is pointed. TJS will get more attention not only for their temperature sensitivity, but for their capability for detecting strains too. The reliability of TJS for detecting residual strains inside composites after curing cycles will be one of the key-points in the incoming research.

\subsection{Flexible Ultrasonic Transducers (FUT)}

After the polymerization process, only the echoes $\mathrm{L}_{\mathrm{m}+\mathrm{c}}$ and $\mathrm{L}_{2 \mathrm{~m}}$ can be employed for the curing monitoring, because they are strong enough. Unfortunately, the echoes $\mathrm{L}_{\mathrm{m}+3 \mathrm{c}}$ and $\mathrm{L}_{2 \mathrm{~m}+2 \mathrm{c}}$ are too weak to be linked with the polymerization phenomena.

Because of the stability and strength of the $\mathrm{L}_{2 \mathrm{~m}}$ echo, one of the main interests is to understand its evolution through the whole curing process in the different zones where the FUT are placed. The other interest is to compare this echo with other signals like thermocouple or FBG measurements. 
The return time of the $\mathrm{L}_{2 \mathrm{~m}}$ echo, reflected from the interface between mould and composite, could be used to represent the temperature variation in the mould during the curing process. Figure 12 shows the temperature variation in the mould by means of the return time of $\mathrm{L}_{2 \mathrm{~m}}$ echo of FUT 3 and the measurements of TC4. Remember that FUT 3 is placed at the current zone on the area of 20 carbon-epoxy plies. The return time and the temperature have similar evolutions, according with the autoclave pre-settings.

If we consider the difference between the depart time and the return time of the echo, this "time delay" of the ultrasonic wave can be analysed as a function of the physical state of the composite material. Time delay variations can be attached to the chemical and physical phenomena happening inside the composite plies. Figure 13 shows the evolution of the time delay for the duration of the curing process. There are five recognizable phases which are described as follows:

S1: phase where mould temperature is a little above the room temperature. In this phase the resin has a lower viscosity which provides a good coupling between the mould and the plies. The time delay decreases and more ultrasonic waves go through the plies.

S2: phase where temperature continues rising till $90^{\circ} \mathrm{C}$. The viscosity of matrix decreases, the speed of sound diminishes and the time delay increases until the point D1. This time delay increment is caused by a partially melting of the resin causing an irregularly impregnation among fibres.

S3: phase corresponding to the $90{ }^{\circ} \mathrm{C}$ plateau. Theoretically, the time delay should not present any change. However, the time delay diminishes gradually until the point D2. In this phase, it is considered that the polymerization reaction starts. The composite morphology defined by the mix of the solid state of the fibres and the glutinous state of the resin could be the cause of ultrasonic fuzziness. Nonetheless, more experiments should been carried out in order to confirm this hypothesis.

S4: phase located during the second temperature slope, from $90{ }^{\circ} \mathrm{C}$ to $120^{\circ} \mathrm{C}$. In this phase, the polymerization reaction is almost fulfilled. The evolution of the time delay presents a point D3, probably related to the matrix jellification. After this point, time delay decreases drastically, because of the matrix reticulation until the signal stabilizes during the composite consolidation. 
S5: phase linked to the composite consolidation. The time delay decreases steadily because of the autoclave cooling. This final reduction is certainly related to the final composite solidification.

As figure 13 shows, echoes time delay treatment is a reliable technique to infer the initial state of composite plates during their manufacturing. FUT are capable to acquire and transmit through-the-thickness ultrasonic waves that can give signs of the physical state of the composite plies and, therefore, to infer qualitative information of the physical phenomena happening during composite curing cycle.

\subsection{Microstructured Optical Fibres (MOF)}

For instance, we are interested to infer the existence of transversal strains on the current zone of the composite plate. Therefore, the measurements obtained by the FBGs of the PCF Strip 2 are treated.

In first place, the sureness of MOF well-functioning has to be proven by comparing the FBGs signals with the reference thermocouples. Figure 14 shows a temperature - wavelength - time diagram for the TC5 and for the two peaks produced by one of the FBG of PCF Strip 2 MOF. As depicted in figure 14, wavelength and temperature evolve in similar ways during the curing cycle, hence, MOF has a good functioning all over the polymerization process. In second place, the insensitivity of peaks' separation to temperature variations must be assured too. Figure 15 illustrates both diffraction peaks (slow and fast) at room temperature $\left(15^{\circ} \mathrm{C}\right)$, and at the middle of both plateaus $\left(90^{\circ} \mathrm{C}\right.$ and $\left.120^{\circ} \mathrm{C}\right)$. Even when the individual wavelengths change, the peaks' separation stays constant throughout the totality of curing cycle. In consequence, peaks' separation presents no sensitivity to temperature.

Because peaks' separation is the main parameter for the MOF, this characteristic was recorded during all curing cycle. Discrepancy on peaks' separation results as consequence of transverse stresses. For that reason, the peaks' separation is an excellent qualitative indication for the presence of transverse strains inside the composite plies. Figure 16 pictures the peaks' separation in the course of the curing cycle. There are five recognizable segments which are described below: 
R1: segment concerning the beginning of the curing cycle until the first plateau at $90^{\circ} \mathrm{C}$. A little increment on peaks' separation is observed before arriving to the plateau. This alteration can be related to plies relaxation because the carbon fibres are drowned in the resin flux.

R2: segment corresponding to the $90^{\circ} \mathrm{C}$ plateau where any change of peaks' separation is perceptible.

R3: segment when temperature rises from $90^{\circ} \mathrm{C}$ to $120^{\circ} \mathrm{C}$ and autoclave pressure increases to 5 bar. When the second temperature slope begins, peaks' separation diminishes gradually until the beginning of $120^{\circ} \mathrm{C}$ plateau. This peaks' separation diminution is a clue for inferring the existence of slight micro-strains inside the carbon-epoxy plies. The drop of the peaks' separation is about $22 \mathrm{pm}$ which corresponds to a compressive transverse strain of $\sim-130 \mu \varepsilon$.

R4: segment including the $120^{\circ} \mathrm{C}$ plateau. Peaks' separation stays constant during the reticulation of composite plies, meaning that no transverse strain is measured by the MOF sensor.

R5: segment during the cooling stage of the composite structure. Peaks' separation presents a remarkable reduction. The cooling down to room temperature is associated with a large decrease of the MOF signal and thus with the development of substantial transverse residual strains in the composite material. The large decrease of the peak separation, $275 \mathrm{pm}$, results in a transverse strain of $\sim-1620 \mu \varepsilon$. With this signal shrinkage, there is a strong evidence that transverse strains appear mainly for the duration of the composite consolidation.

As figure 16 shows, the evolution of MOF peaks' separation is a trustworthy practice to observe the appearance of transverse strains during the composite curing. MOFs can detect qualitative information of residual stresses in the composite plies. Nonetheless, the estimation of the residual stresses is a need that will be answered in further work.

\section{Conclusions}

A multi-instrumentation setup is placed for the monitoring of a composite plate during its curing cycle to know the initial state of a composite structure after its manufacturing process. 
A carbon-epoxy plate with two drop-offs is instrumented, in-core and at its surface, with 23 devices such as tunnelling junction sensors (TJS), flexible ultrasonic transducers (FUT), micro-structured optical fibres (MOF) and thermocouples (TC).

For the tunnelling junction sensors (TJS), temperature - voltage - time diagram is built to link the temperature changes in the composite plate and the TJS voltage changes. The TJS sensitivity has an average value of $-5 \pm 0.2 \mathrm{mV} /{ }^{\circ} \mathrm{C}$ for a current polarization between 2.5 and $4 \mathrm{~mA}$.

An assembly of flexible ultrasonic transducers (FUT) detected the composite curing phases. Mould-composite coupling, passing through resin reticulation and finishing with composite consolidation are identified. The viability of FUT to estimate the composite polymerization evolution is proved.

A new technology of micro-structured optical fibres (MOF) is applied to estimate the presence of transverse strains inside the composite plate. The evolution of peaks' separation for the embedded MOF shows quantitative indications of the appearance of transverse strains, in this study case up to $1600 \mu \varepsilon$, at the composite cooling down, which are related to residual stresses.

Finally, the results from the multi-instrumentation show the complementary potential of all these new technologies for monitoring the curing cycle of complex composite structures. Further work will be focused on the estimation of curing residual stresses as depart to estimate the in-service strength of composite structures.

\section{Acknowledgments}

The present work is part of the research project "Multi-sensor Instrumentation for Composite Materials and Structures (I2MC)" financially supported by the Thematic Advanced Research Network for Aeronautics and Space Sciences \& Technologies of Toulouse (RTRA STAE).

M. Torres conveys his special appreciation to the National Council of Science and Technology of Mexico (CONACYT) for the financial support to pursue his graduate studies and to the Research Fellowship Program (Cátedras CONACYT) for his current job position. 


\section{References}

1. Rouse, M.; Jegley, D.C.; McGowan, D.M.; Bush, H.G.; Waters, W.A. Utilization of the Building-Block Approach in Structural Mechanics Research; NASA: Greenbelt, CA, USA, 2005; pp. 105-116.

2. Hernández H, Collombet F, Douchin B, Choqueuse D, Davies P, González JL. Entire lifetime monitoring of filament wound composite cylinders using Bragg grating sensors: II. Process Monitoring. Applied Composites Materials, 2009; 16/4: 197-209.

3. Mulle M, Zitoune R, Collombet F. Through-the-thickness material properties identification in a technological specimen using 3D-DIC and embedded FBG measurements. Experimental Mechanics, 2008; 1340-1343.

4. Mulle M, Zitoune R, Collombet F, Olivier P, Grunevald YH. "Thermal expansion of carbon-epoxy laminates measured with embedded FBGS - Comparison with other experimental techniques and numerical simulation". Composites Part A, 2007; 38: 1414-1424.

5. Dunkers JP, Lenhart JL, Kueh SR, van Zanten JH, Advani SG, Parnas RS. Fiber optic flow and cure sensing for liquid composite molding. Optics and Lasers in Engineering, 2001; 35: 91-104.

6. Lekakou C, Cooka S, Denga Y, Angb TW, Reed GT. Optical fibre sensor for monitoring flow and resin curing in composites manufacturing. Composites Part A, 2006; 37: 934 938.

7. Grande AM, Di Landro L, Bettini P, Baldi A, Sala G. RTM process monitoring and strain acquisition by fibre optics. Procedia Engineering, 2011; 10: 3497-502.

8. Tuncol G, Danisman M, Kaynar A, Sozer EM. Constraints on monitoring resin flow in the resin transfer molding (RTM) process by using thermocouple sensors. Composites Part A, 2007; 38: 1363-1386.

9. Sobotka V, Lefevre N, Jarny Y, Delaunay D. Inverse methodology to determine mold set-point temperature in resin transfer molding process. International Journal of Thermal Sciences, 2010; 49: 2138-2147.

10. Di Fratta C, Klunker F, Ermanni P. A methodology for flow-front estimation in LCM processes based on pressure sensors. Composites Part A, 2013; 47: 1-11.

11. Matsuzaki R, Kobayashi S, Todoroki A, Mizutani Y. Cross-sectional monitoring of resin impregnation using an area-sensor array in an RTM process. Composites Part A, 2012; 43: 695-702. 
12. Yenilmez B, Sozer EM. A grid of dielectric sensors to monitor mold filling and resin cure in resin transfer molding. Composites Part A, 2009; 40: 476-489.

13. Boll D, Schubert K, Brauner C, Lang W. Miniaturized flexible interdigital sensor for In situ dielectric cure monitoring of composite materials. IEEE Sensors Journal, 2014; 14 (7): 2193-2197.

14. Khoun L, de Oliveira RD, Michaud V, Hubert P. Investigation of process-induced strains development by fibre Bragg grating sensors in resin transfer moulded composites. Composites Part A, 2011; 42: 274-282.

15. Jung K, Kang TJ. Cure monitoring and internal strain measurement of 3-d hybrid braided composites using fiber Bragg grating sensor. Journal of Composite Materials, 2007; 41: 1499-1519.

16. Torres M, Collombet F, Douchin B, Crouzeix L, Grunevald Y.H, Lubin J, Camps T. Monitoring of the curing process of composite structures by tunnelling junction sensors. Sensors and Actuators A, 2015; 235: 256-264.

17. Torres M, Tellez RA, Hernández $\mathrm{H}$, Camps T. Mode I interlaminar fracture toughness of carbon- epoxy coupons with embedded ceramic sensors. Advances in Polymer Technology, 2017; 37(6): 2294-2302.

18. Collombet F, Luyckx G, Sonnenfeld C, Grunevald YH, Davila Y, Torres M, Jacob X, Wu KT, Rodriguez S, Douchin B, Crouzeix L, Bazer-Bachi R, Geernaert T, Degrieck J, Berghmans F. Cure monitoring of an autoclave manufactured industrial part: added value of complementary instrumentation. Proceedings of the 19th International Conference on Composite Materials (ICCM), Montréal, Canada; 2013.

19. Kobayashi M, Jen CK. Piezoelectric thick bismuth titanate/PZT composite film transducers for smart NDE of metals. Smart Materials Structures 2004; 13: 951-956.

20. Kobayashi M, Jen CK, Bussiere JF, Wu KT. High-temperature integrated and flexible ultrasonic transducers for non-destructive testing. NTD \& E International, 2009; 42: 157-161.

21. Chehura E, Ye CC, Staines SE, James SW, Tatam RP. Characterization of the response of fibre Bragg gratings fabricated in stress and geometrically induced high birefringence fibres to temperature and transverse load. Smart Materials and Structures, 2004; 13 : 888-895.

22. Frazao O, Carvalho J P, Ferreira L A, Araujo F M, Santos J L. Discrimination of strain and temperature using Bragg gratings in microstructured and standard optical fibres. Measurement Science and Technology, 2005; 16: 2109-2113. 
23. Luyckx G, Voet E, De Waele W, Degrieck J. Multi-axial strain transfer from laminated CFRP composites to embedded Bragg sensor: I. Parametric study. Smart Materials and Structures, 2010; 19: 1-9.

24. Voet E, Luyckx G, De Waele W, Degrieck J. Multi-axial strain transfer from laminated CFRP composites to embedded Bragg sensor: II. Experimental validation. Smart Materials and Structures, 2010; 19: 10-18.

25. Geernaert T, Becker M, Mergo P, Nasilowski T, Wojcik J, Urbanczyk W, Manfred Rothhardt, Chojetzki C, Bartelt H, Terryn H, Berghmans F, Thienpont H. Bragg grating inscription in GeO2-doped microstructured optical fibers. Journal of Lightwave Technology, 2010; 28: 1459-1467.

26. Lammens N, Kinet D, Chah K, Luyckx G, Caucheteur C, Degrieck J, Mégret P. Residual strain monitoring of out-of-autoclave cured parts by use of polarization dependent loss measurements in embedded optical fiber Bragg gratings. Composites Part A, 2013; 52: 38-44.

27. Sonnenfeld C, Luyckx G, Collombet F, Grunevald YH, Douchin B, Crouzeix L, Torres M, Geernaert T, Sulejmani S, Chah K, Mergo P, Thienpont H, Berghmans F. Cure cycle monitoring of laminated carbon fiber-reinforced plastic by fiber Bragg gratings in micro-structured optical fiber. Proceedings of the 19th International Conference on Composite Materials (ICCM), Montréal, Canada; 2013.

28. Sonnenfeld C, Luyckx G, Collombet F, Grunevald YH, Douchin B, Crouzeix L, Torres M, Geernaert T, Sulejmani S, Eve S, Gomina M, Chah K, Mergo P, Thienpont H, Berghmans F. Embedded fiber Bragg gratings in photonic crystal fiber for cure cycle monitoring of carbon fiber-reinforced polymer materials. Micro-structured and Specialty Optical Fibres II, 2013; 877500.

29. Kim S, Murayama H, Kageyama K, Uzawa K, Kanai M. Study on the curing process for carbon/epoxy composites to reduce thermal residual stress. Composites Part A: Applied Science and Manufacturing, 2012; 43/8: 1197-1202.

30. Guiming Z, Jihui W, Aiqing N, Shuxin L. Process-induced residual stress of variablestiffness composite laminates during cure. Composite Structures, 2018; 204: 12-21.

31. Lu S, Chen D, Wang X, Shao J, Ma K, Zhang L, et al. Real-time cure behaviour monitoring of polymer composites using a highly flexible and sensitive CNT bucky paper sensor. Composite Sciences and Technology, 2017; 152: 181-189. 
32. Wang Ya, Wang Y, Zhang P, Liu F, Luo S. Laser-induced freestanding graphene papers: A new route of scalable fabrication with tunable morphologies and properties for multifunctional devices and structures. Small, 2018:1802350

33. Luo S, Wang Y, Wang G, Wang K, Wang Z, Zhang C, Wang B, Luo Y, Li L, Liu T. CNT enabled co-braided smart fabrics: A new route for non-invasive, highly sensitive \& large-area monitoring of composites. Scientific Reports, 2017: 7, 44056.

34. Ali MA, Umer R, Khan KA, Samad YA, Liao K, Cantwell W. Graphene coated piezoresistive fabrics for liquid composite molding process monitoring. Composites Science and Technology, 2017, 148: 106-114.

35. Van Velthem P, Ballout W, Dumont D, Daoust D, Sclavons M, Cordenier F, Pardoen T, Devaux J, Bailly C. Phenoxy nanocomposite carriers for delivery of nanofillers in epoxy matrix for resin transfer molding (RTM)-manufactured composites. Composites Part A, 2015; 76: 82-91.

36. Doshi SM, Thostenson ET. Self-sensing carbon nanotube composites: processing and characterization. Multifunctionality of Polymer Composites: Challenges and New Solutions, 2015; Chapter 25, 752-784.

37. Tzounis L, Zappalorto M, Panozzo F, Tsirka K, Maragoni L, Paipetis AS, et al. Highly conductive ultra-sensitive SWCNT-coated glass fiber reinforcements for laminate composites structural health monitoring. Composites Part B, 2019; 169: 37-44.

38. Luo Sida, Wang Guantao, Wang Yong, Xu Ye, Luo Yun. Carbon nanomaterials enabled fiber sensors: A structure-oriented strategy for highly sensitive and versatile in situ monitoring of composite curing process. Composites Part B: Engineering, 2019, 166: 645-652.

39. Torres M. Parameters' monitoring and in-situ instrumentation for resin transfer moulding: A review. Composites Part A, 2019, 124: 105500.

40. Torres M, Crouzeix L, Collombet F, Douchin B, Grunevald YH. Assessments on the mechanical behaviour of a monolithic composite structure instrumented with a monitoring patch. Journal of Composite Materials, 2017; 51: 3597-3610.

41. Torres M, Crouzeix L, Collombet F, Douchin B, Grunevald Y.H. Numerical and experimental value added of multi-instrumented technological evaluator for the analysis of thick monolithic composite structures with singularity details. Composite Structures, 2015; 127: 41-50.

42. Grunevald YH. Value Added of MITE toolbox on development of a full composite railway bogie, comparison with a classical approach. Proceedings of the $7^{\text {th }}$ 
International Conference on Rapid Product Development, Saint Dié des Vosges, France, 2009. 
MULTI-INSTRUMENTATION MONITORING FOR THE CURING PROCESS OF A COMPOSITE STRUCTURE.

\section{Graphical Abstract}
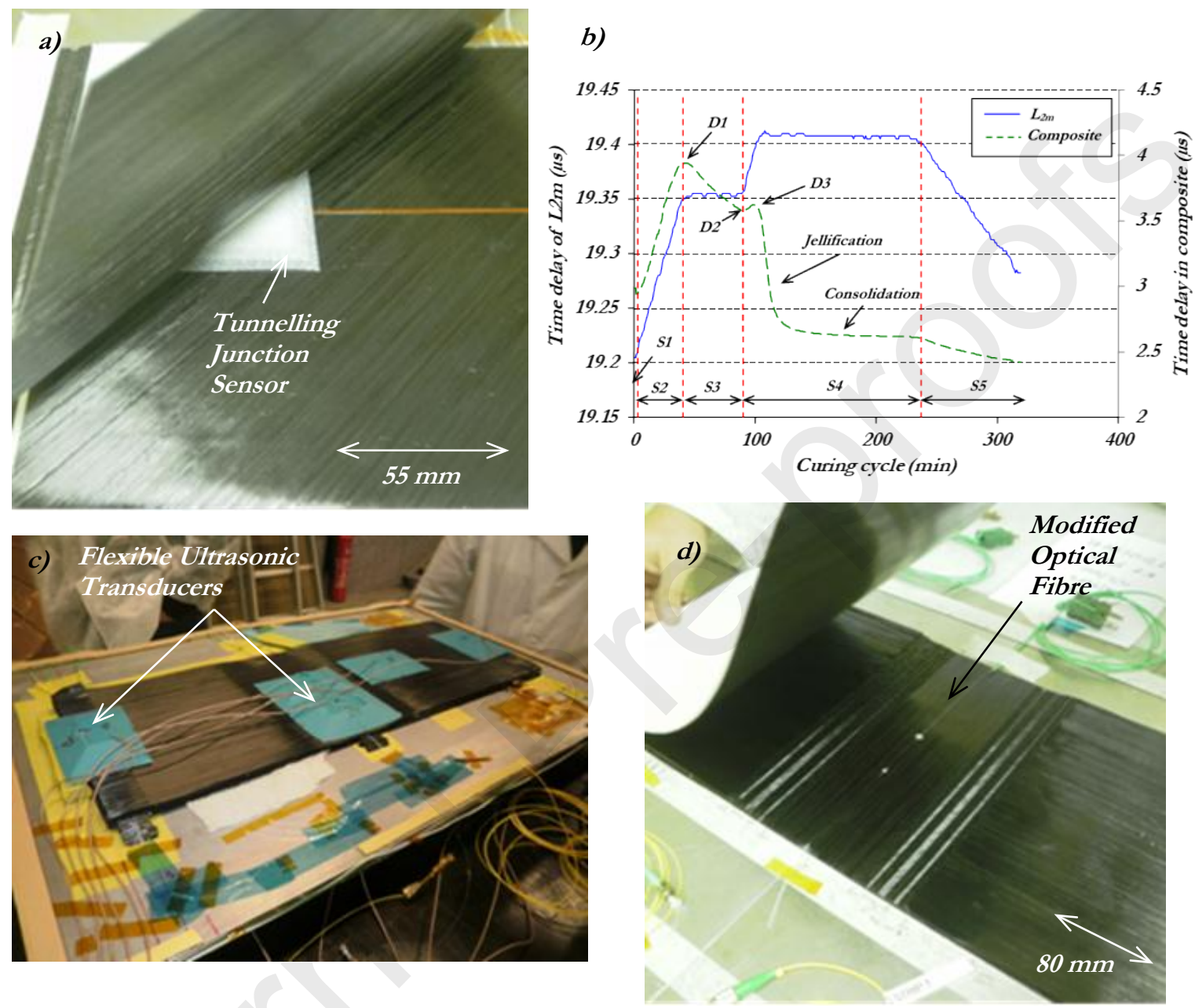

Multi-instrumented composite plate for curing monitoring. 
MULTI-INSTRUMENTATION MONITORING FOR THE CURING PROCESS OF A COMPOSITE STRUCTURE.

\section{Highlights:}

1. The use Tunnelling Junctions Sensors (TJS) for monitoring temperature variations in composite curing.

2. The use of Flexible Ultrasonic Transducers (FUT) for monitoring phase change in thermoset resin consolidation.

3. The use of Modified Optical Fibres (MOF) for monitoring residual strains in composite cooling.

4. The embedding of three different sensor technologies inside a carbon-epoxy composite plate to track temperature, strains and polymerization during its curing process. 
a)

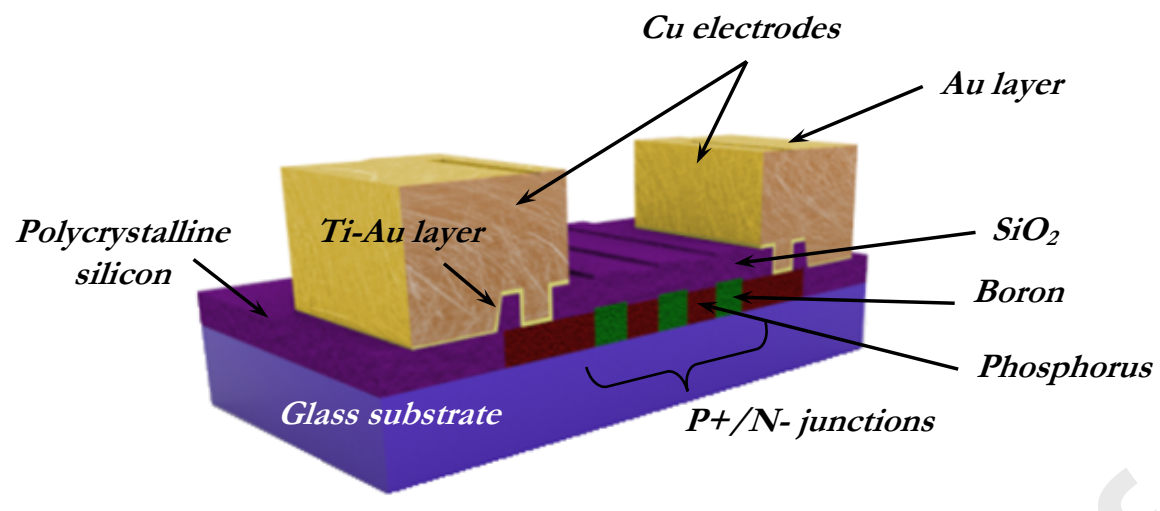

b)

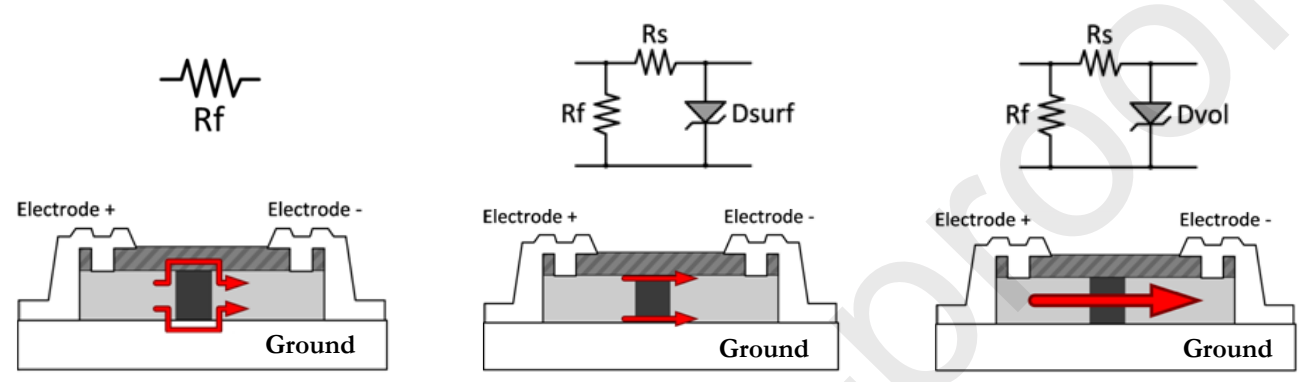

c)

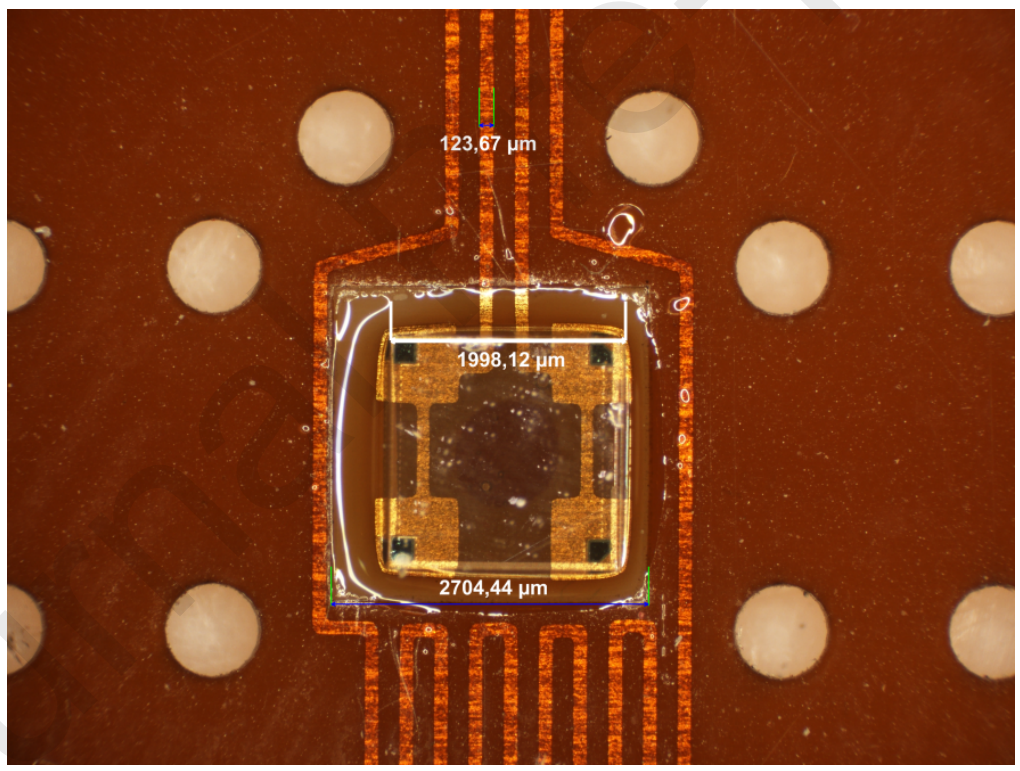

Figure 1. a) Schematic of the TJS manufactured by LPCVD, b) equivalent circuits for the TJS behaviours in different current regimes, $b$ and $c$ ) micrograph of the assembled TJS. 
a) Al plate $(6 \mathrm{~mm})$

Teflon foil (1 mm)

Plate FUT

Composite
plate

Al mould

(15 mm)

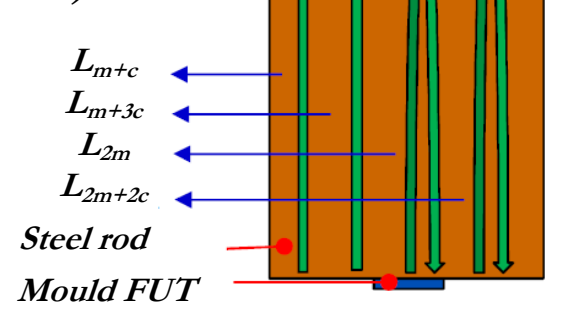

b)

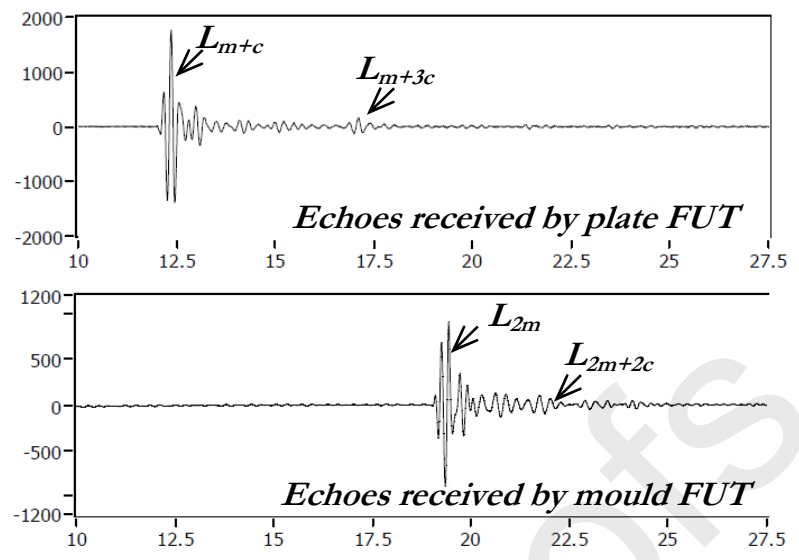

Figure 2. Schemes of a) the FUT assembly and b) the different echoes produced by the FUT for composites curing monitoring.

a)

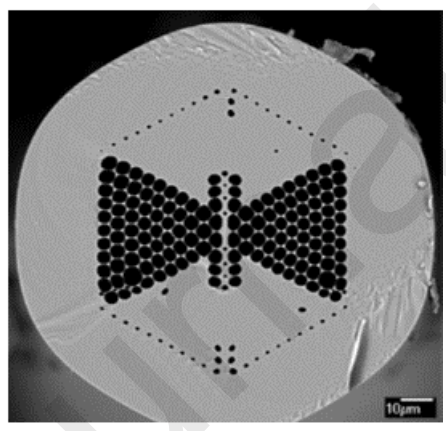

b)

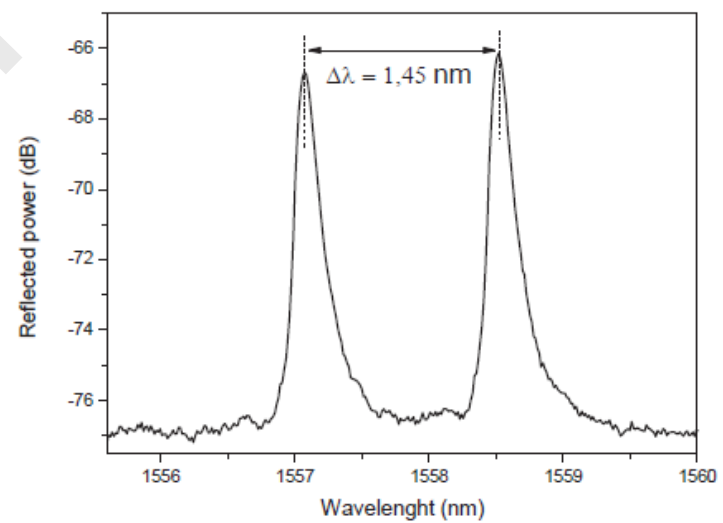

Figure 3. a) SEM of a MOF cross-section and b) Bragg grating spectrum with the peak separation $(\Delta \lambda)$. 
a)

Over-thick zone Drop-offs

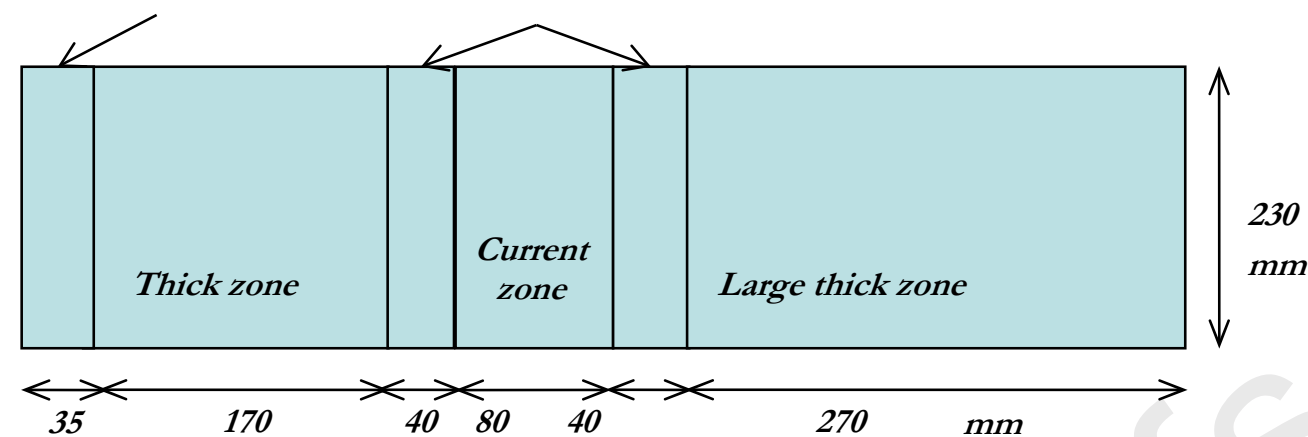

b) 52 plies $\quad 36$ plies Drop-offs

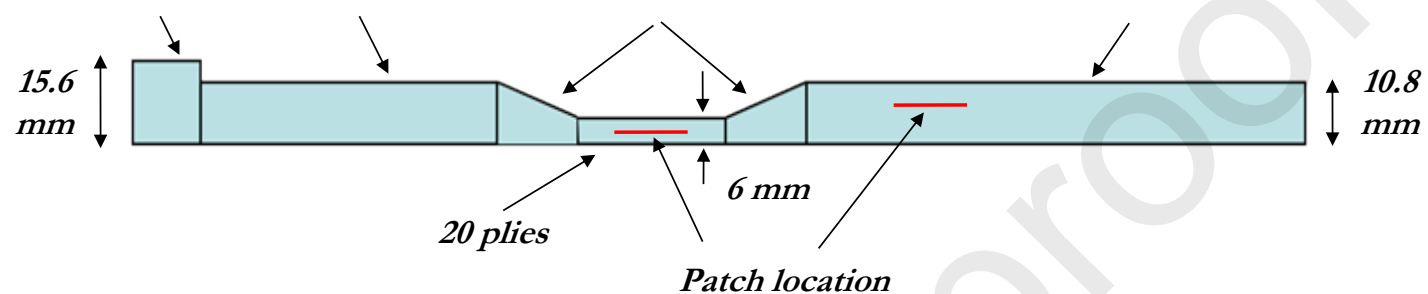

Figure 4. Composite plate design lay-up for its curing monitoring.

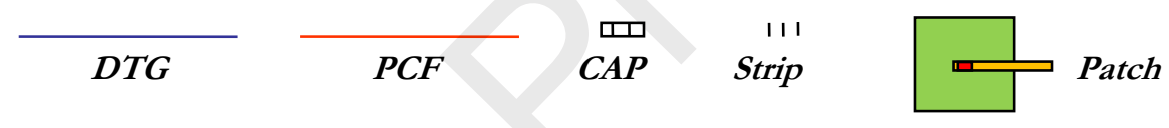

\section{Current}

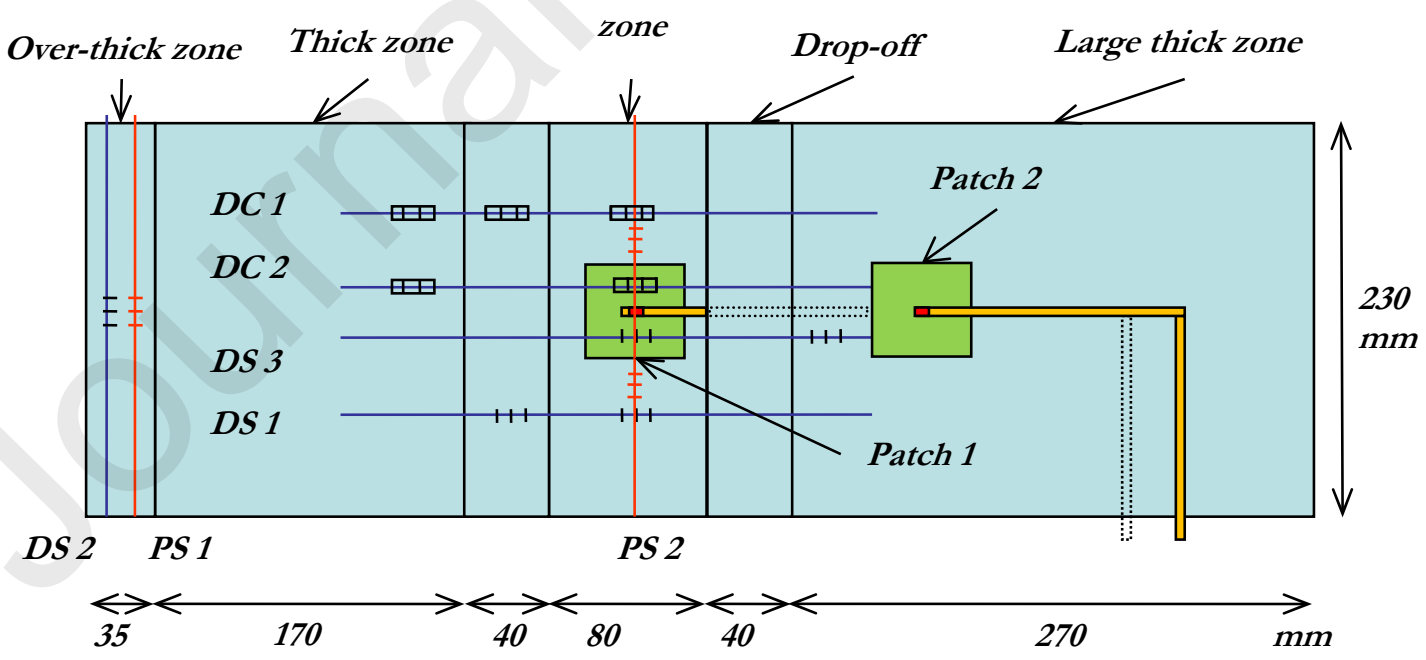

Figure 5. In-core instrumentation for monitoring the composite curing cycle. 


$\begin{array}{lll}\text { Embedded } & \begin{array}{l}\text { Surface } \\ \text { thermocouple }\end{array} \text { thermocouple }\end{array} \quad \begin{aligned} & \text { FUT at } \\ & \text { mould }\end{aligned} \| \begin{aligned} & \text { FUT at } \\ & \text { composite }\end{aligned}$

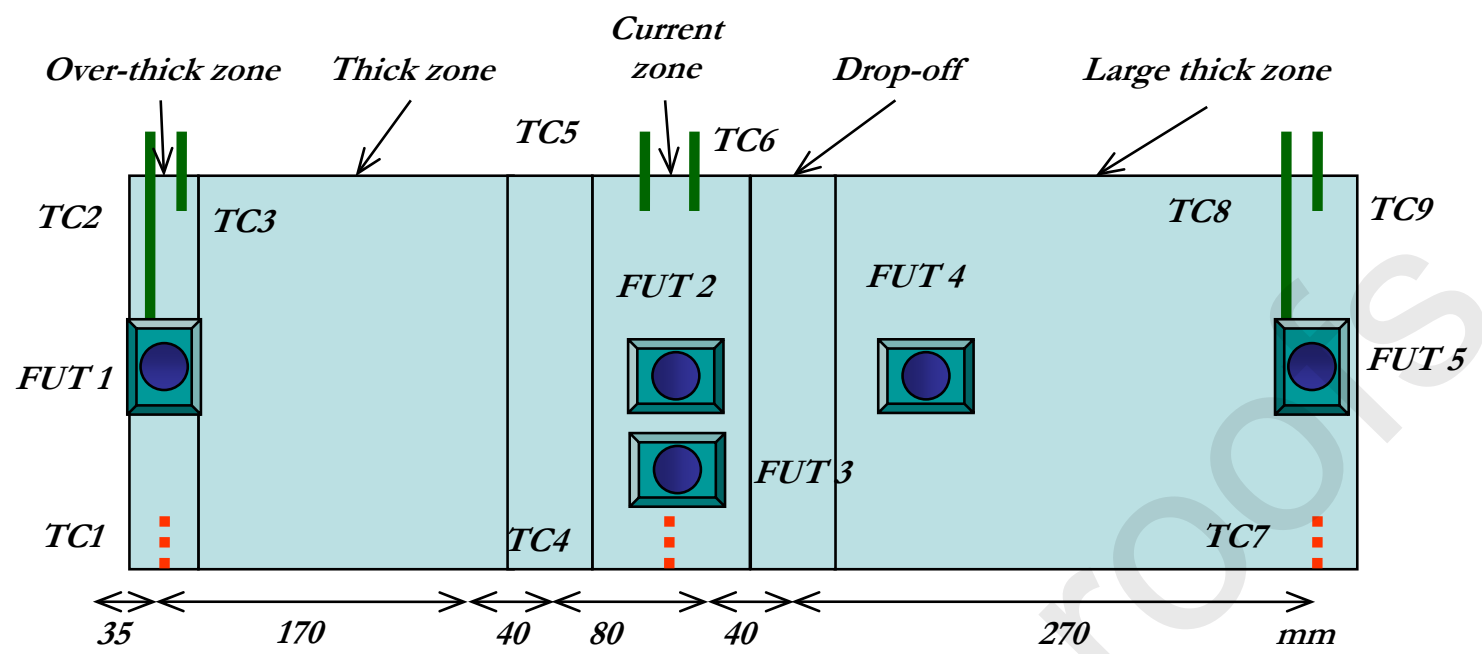

Figure 6. Surface instrumentation and reference thermocouples for monitoring the composite curing cycle. 

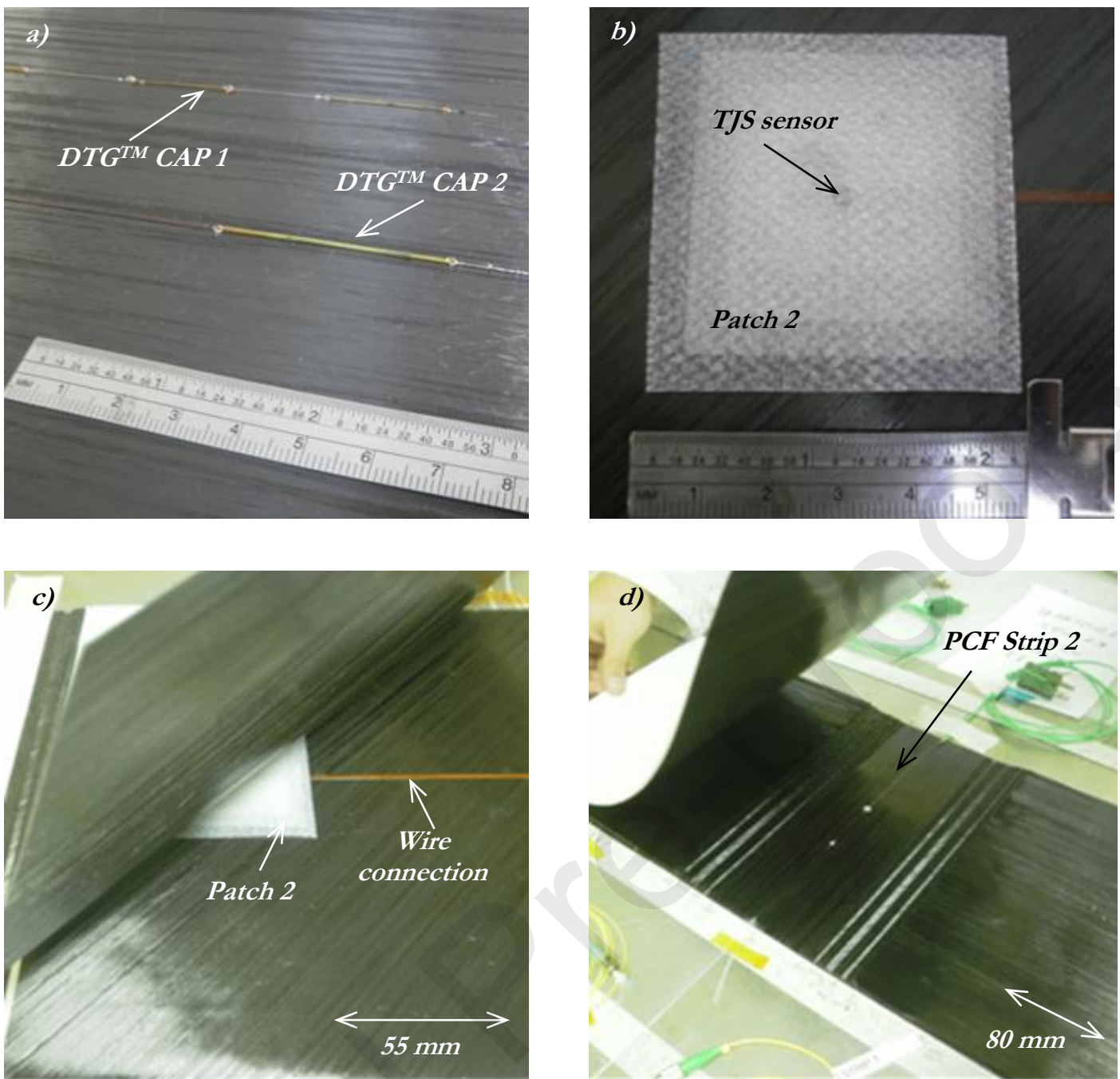

Figure 7. Illustrations for the lay-up procedure: a) embedding of the DTG ${ }^{\mathrm{TM}}$ optical fibres, b) embedding of TJS in the monitoring patch, c) embedding of monitoring patch in composite plate and d) embedding of PCF optical fibres. 

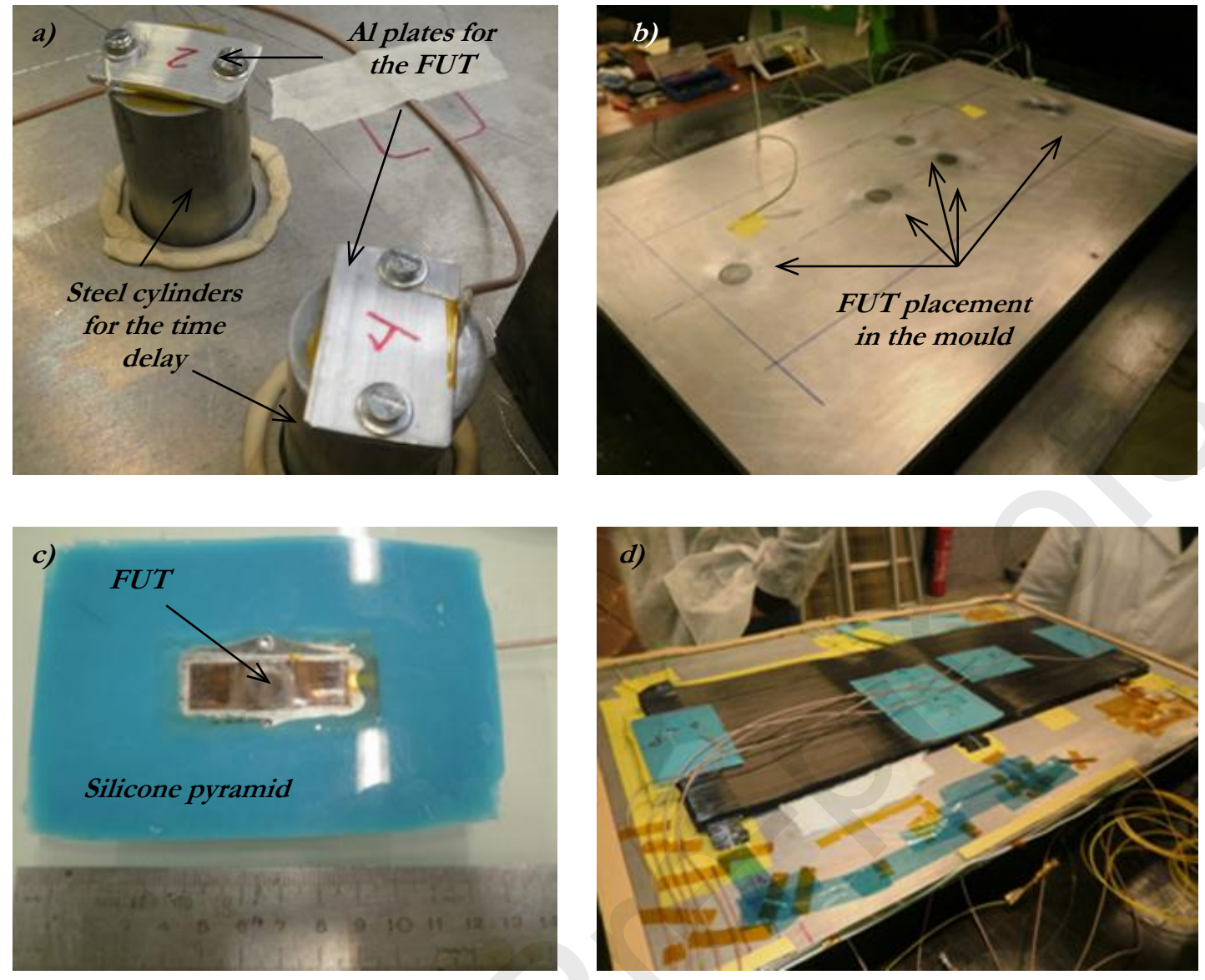

Figure 8. Illustrations of the general adaptations for the experimental set-up: a) FUT's mould adaptation, b) placement for the FUT acquisitions, c) silicone pyramid for the composite FUT and d) final disposition of instrumented composite plate.

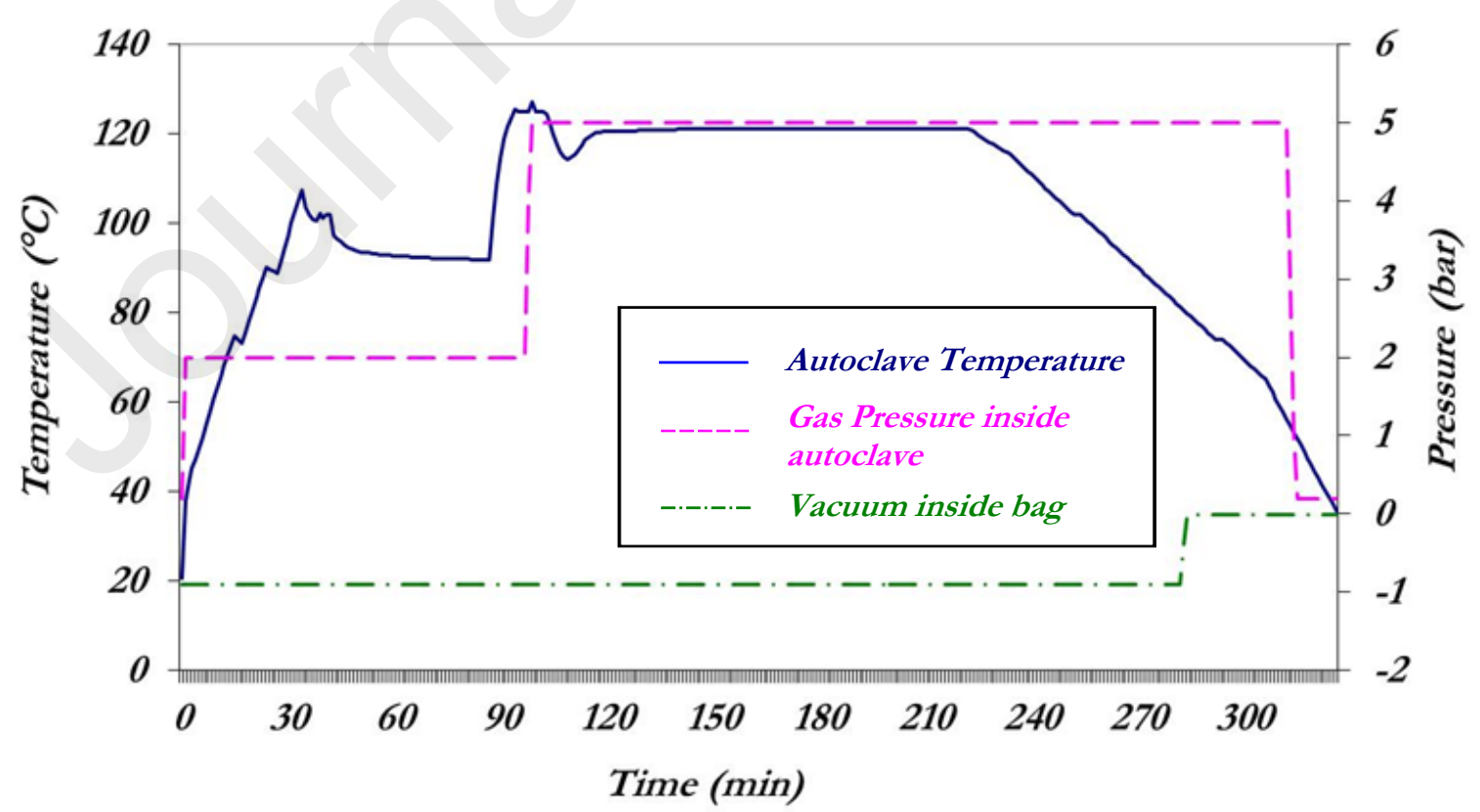

Figure 9. Autoclave settings for the polymerization cycle [10]. 


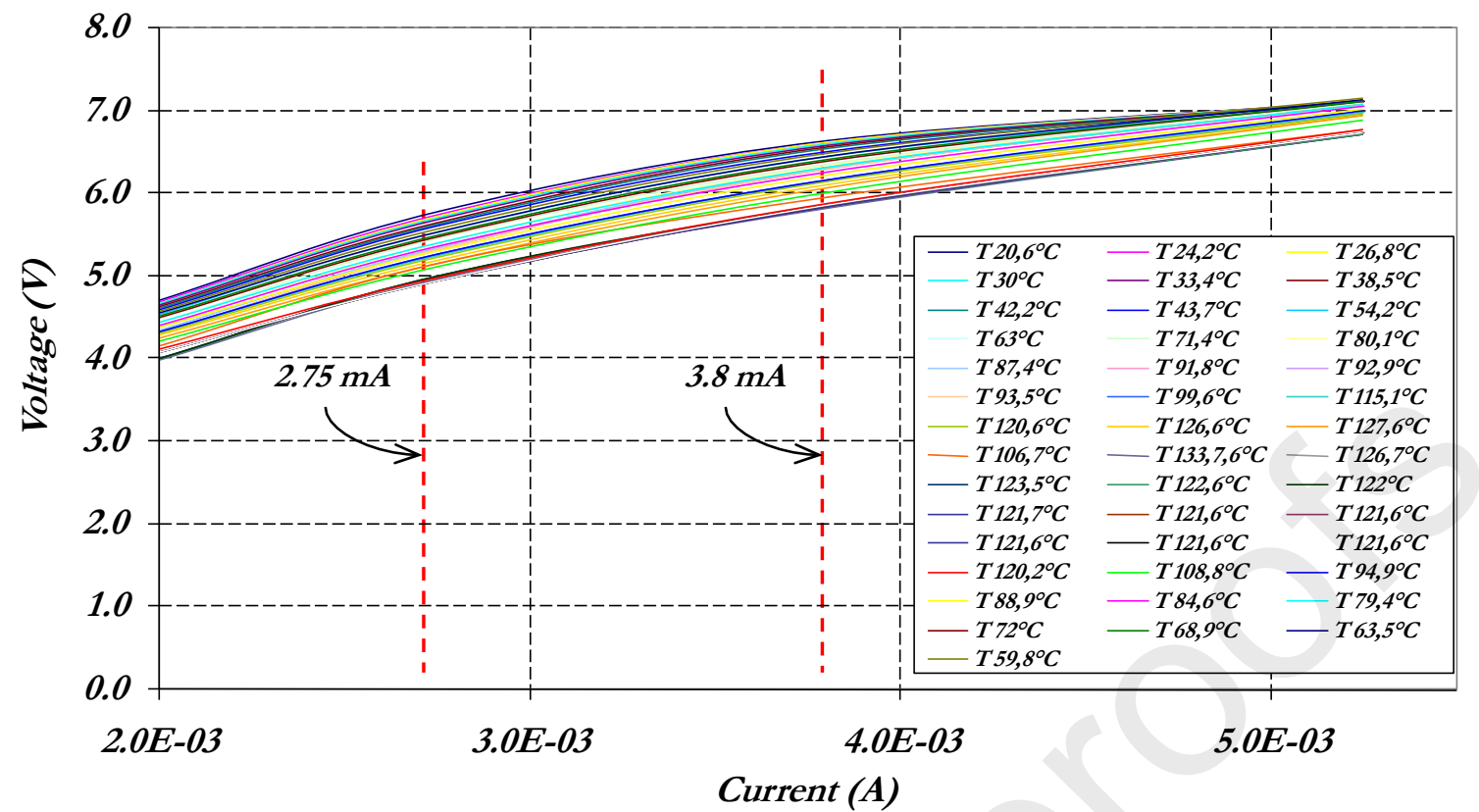

Figure 10. Measurement range for the tunnelling junction sensor (TJS).

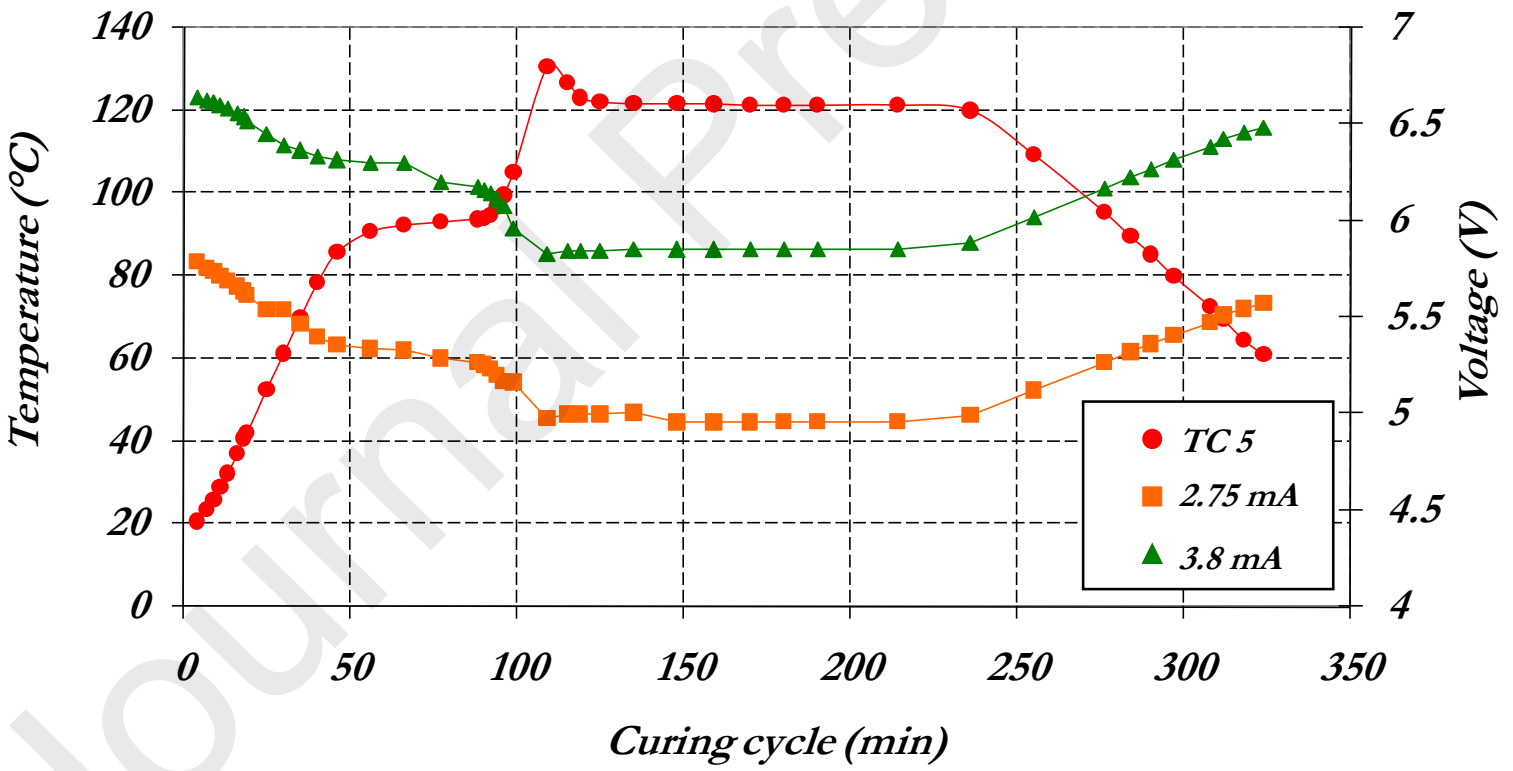

Figure 11. Temperature - voltage - time diagram for the tunnelling junction sensor (TJS) [16]. 


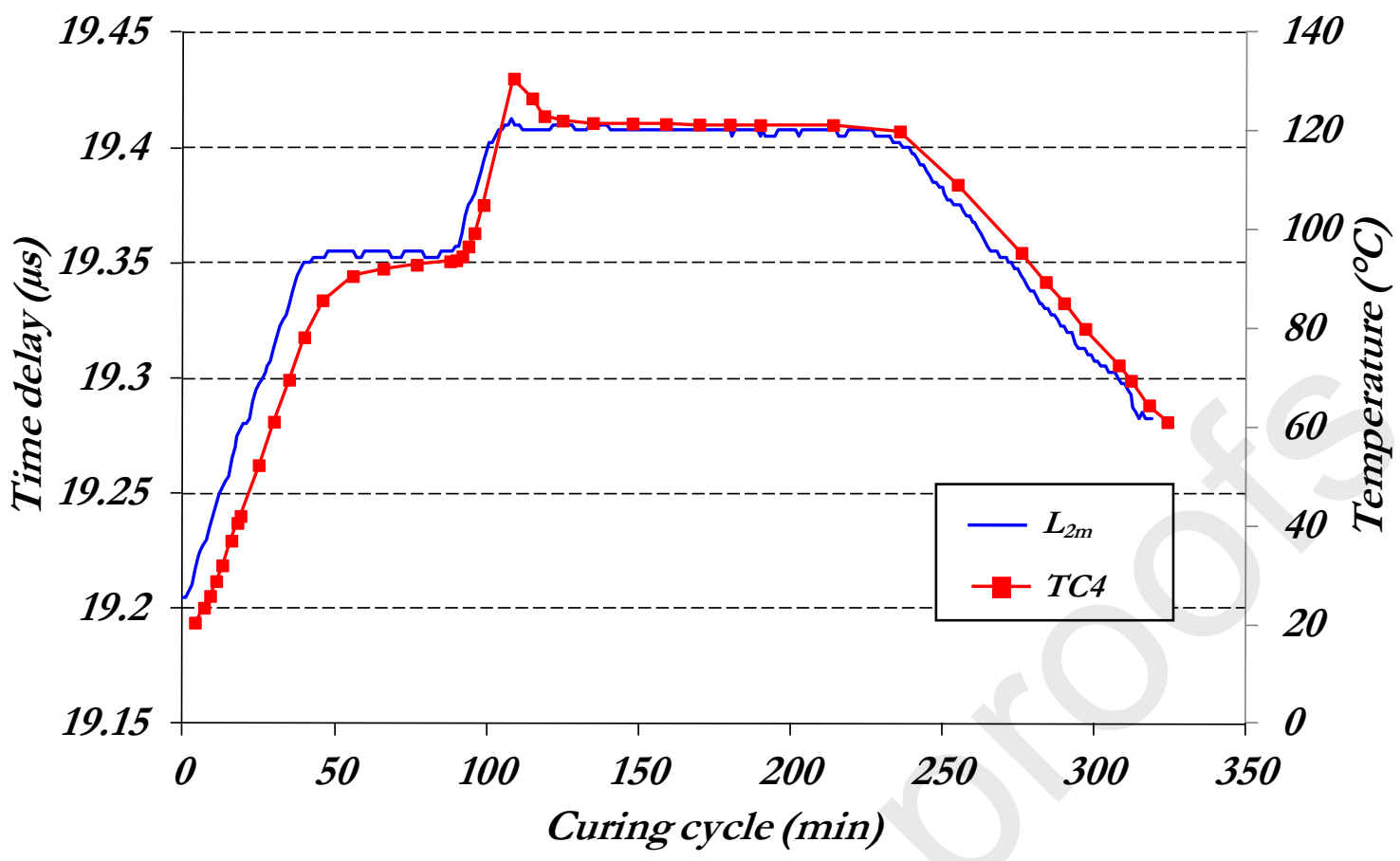

Figure 12. Evolution for the FUT signal ( $\mathrm{L}_{2 \mathrm{~m}}$ echo) and the temperature (TC4) during the curing cycle.

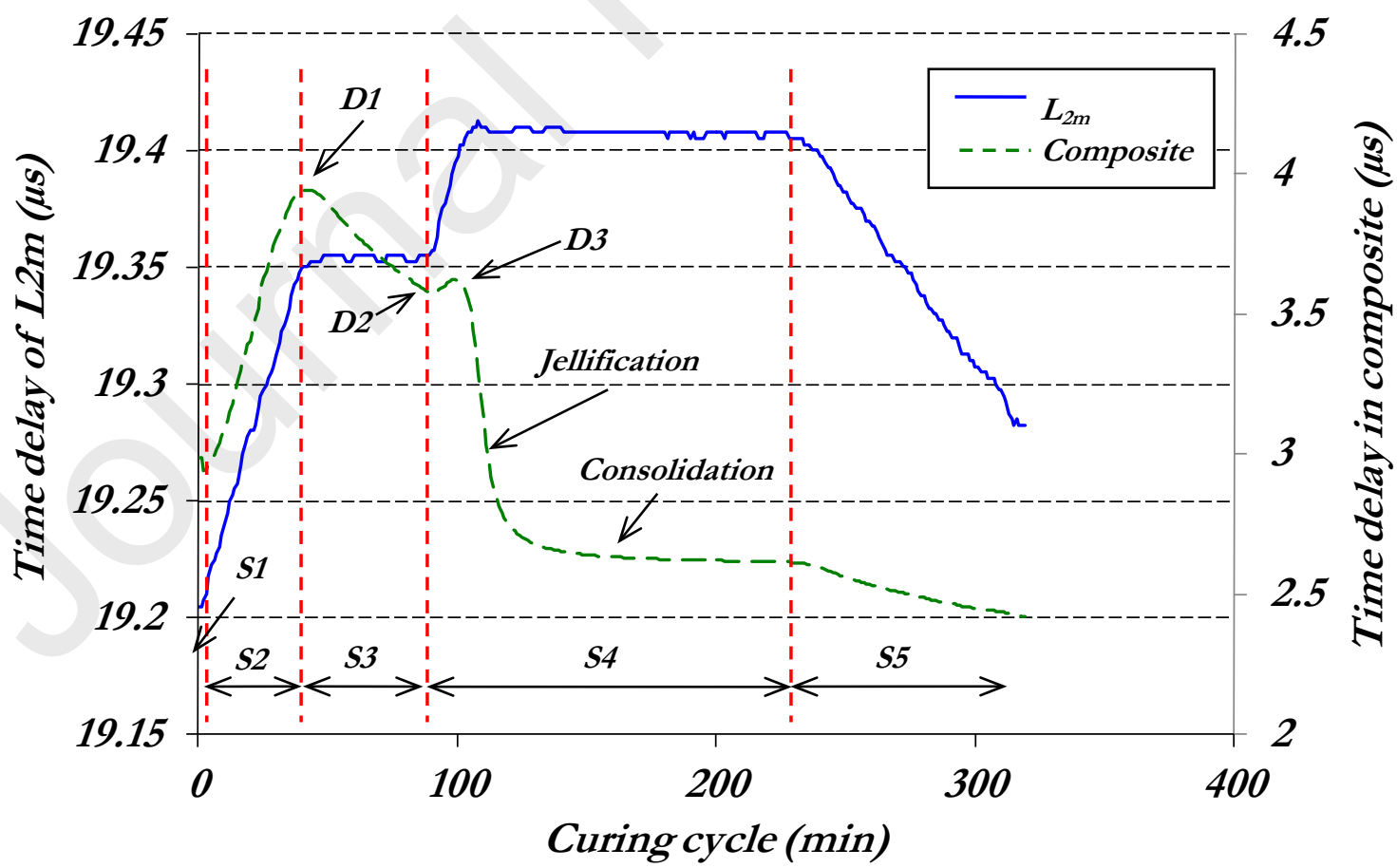

Figure 13. Evolution of the time delay in the composite plate during the curing cycle. 


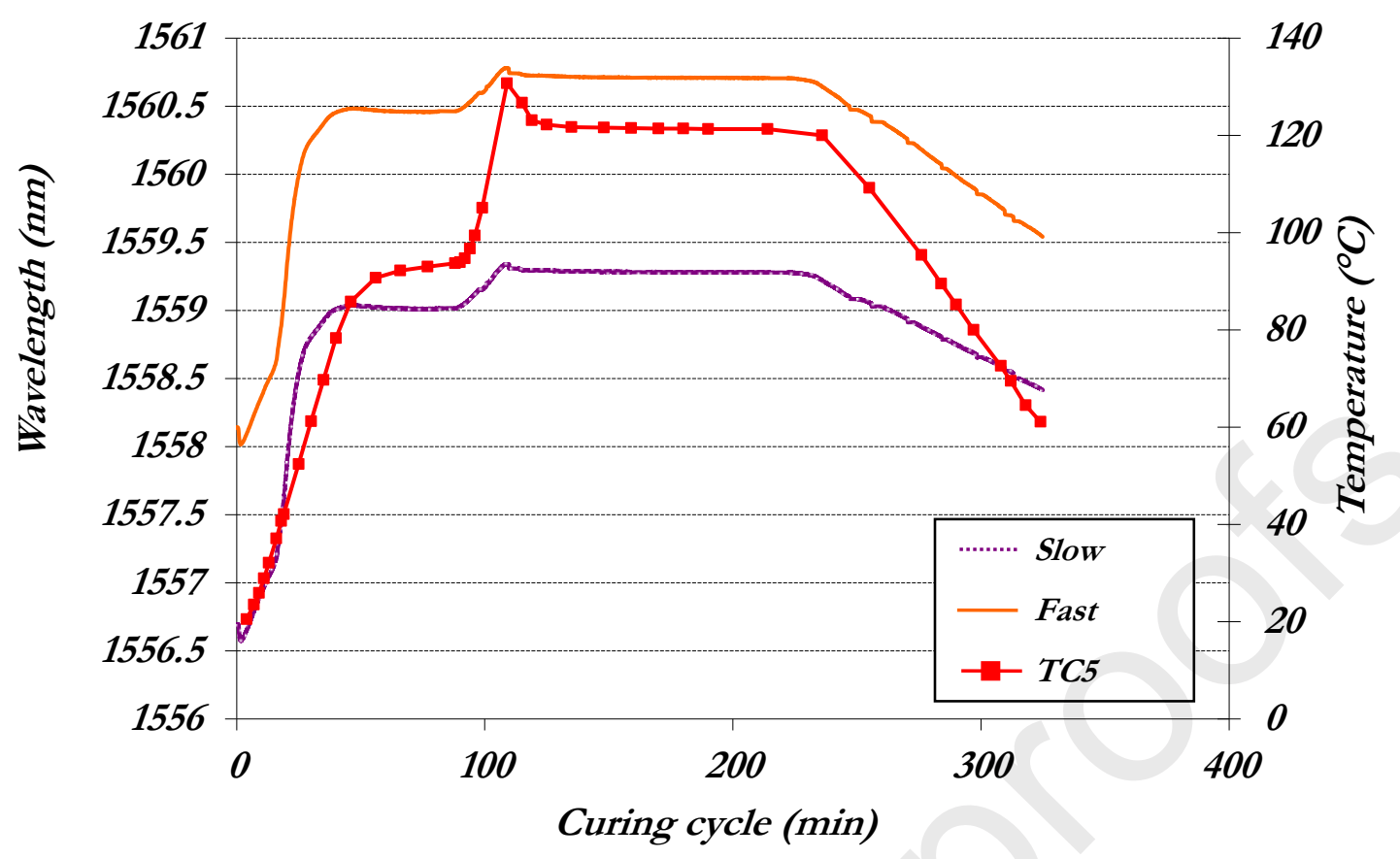

Figure 14. Evolution of wavelength for the two peaks of FBG 1 of PCF Strip 2 MOF during curing cycle. 


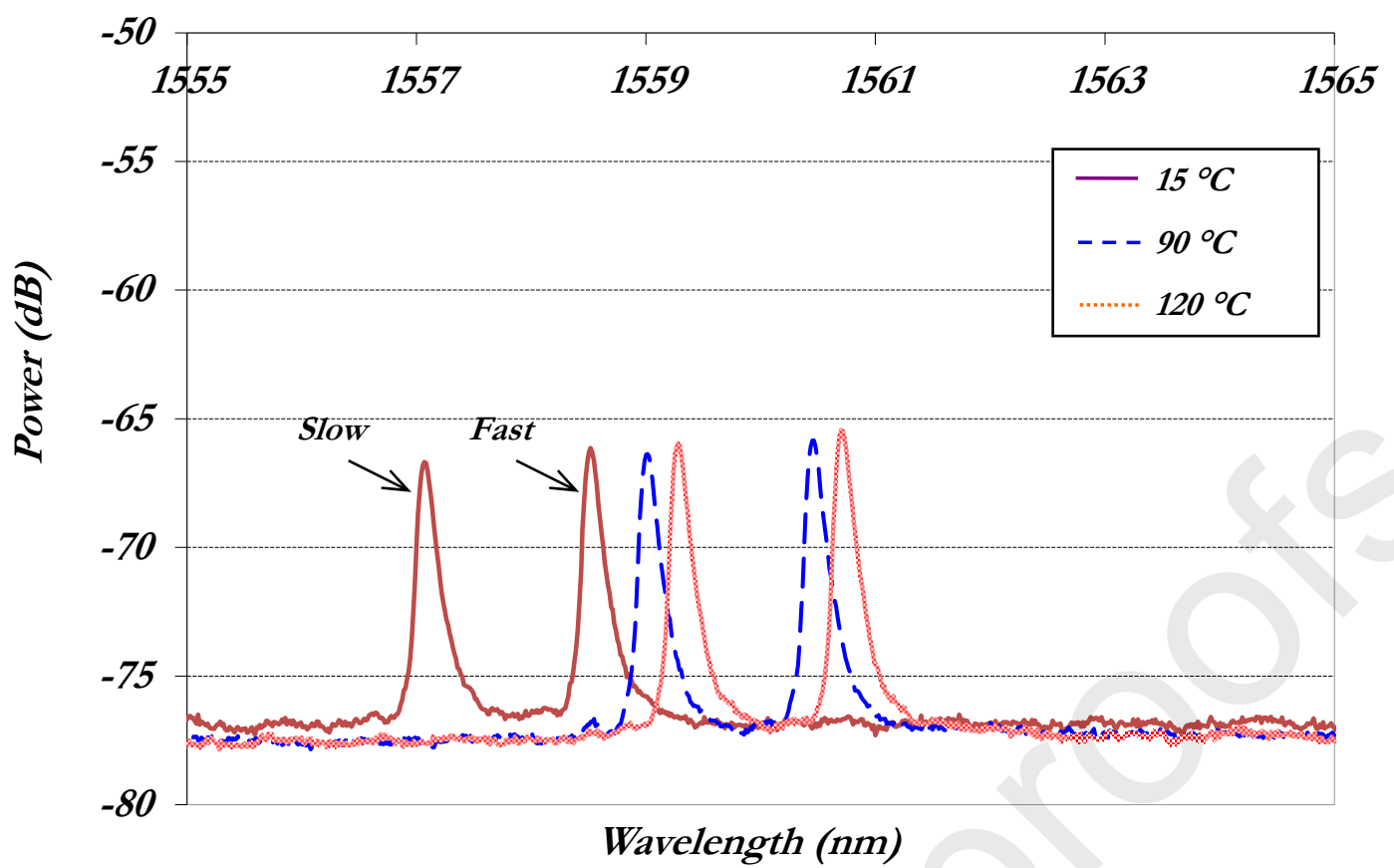

Figure 15. Peaks separation at different temperatures for the FBG 1 of PCF Strip 2 during the curing cycle. The temperature does not affect the value of the peak's separation.

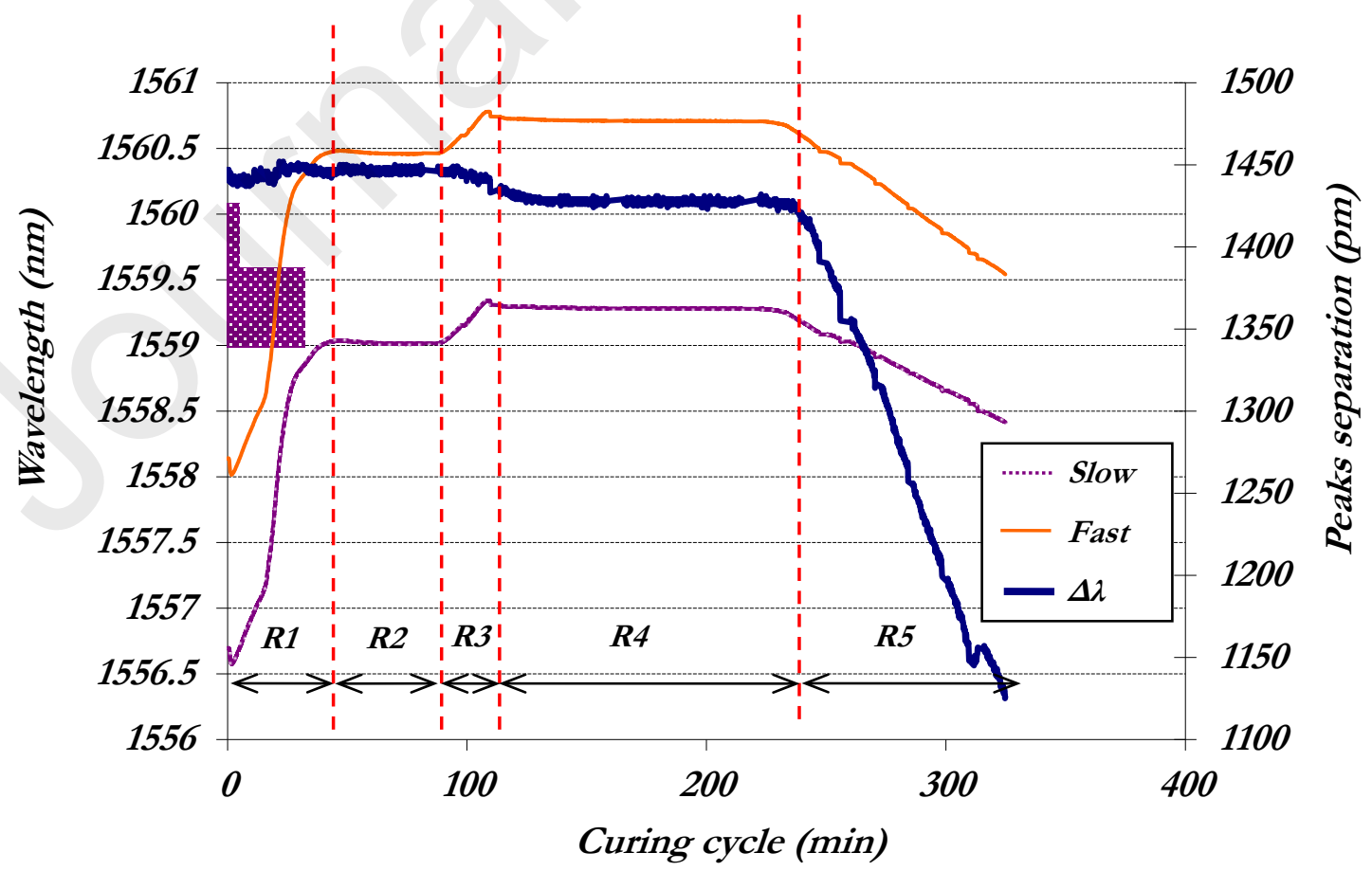


Figure 16. Evolution of peaks separation $(\Delta \lambda)$ for the two peaks of FBG 1 of PCF Strip 2 MOF during curing cycle. 
MULTI-INSTRUMENTATION MONITORING FOR THE CURING PROCESS OF A COMPOSITE STRUCTURE.

\section{Author Statement}

Mauricio Torres Arellano* Investigation, Data curation, Formal analysis, Validation, Visualization, Writing - original draft, Writing - review \& editing.

Francis Collombet Conceptualization, Methodology, Funding acquisition Project administration, Supervision, Resources.

Bernard Douchin Investigation, Writing - review \& editing.

Laurent Crouzeix Investigation, Formal analysis.

Yves-Henri Grunevald Investigation, Methodology, Formal analysis, Validation.

Jerome Lubin Investigation, Data curation, Formal analysis.

Thierry Camps Formal analysis.

Xavier Jacob Investigation, Data curation, Formal analysis, Visualization.

Geert Luyckx Investigation, Data curation, Formal analysis, Validation, Visualization, Writing - review \& editing.

Kuo Ting Wu Investigation, Data curation, Validation, Visualization, Writing - review \& editing. 
MULTI-INSTRUMENTATION MONITORING FOR THE CURING PROCESS OF A COMPOSITE STRUCTURE.

All authors confirm that they have mentioned all organizations that funded this research in the Acknowledgements section of your submission, including grant numbers where appropriate.

The authors inform that this work, in its present form, has been already been submitted to another journal. The present article was not rejected previously.

All authors confirm that there is not conflict of interest of the present paper. 